\title{
Yönetim Süreçlerinin Etkililiğinin İncelenmesi: Yönetim Anlayışı, Bürokratik Yapı ve Kültürel Değerler Bağlamında Çoklu ve Bütüncül Bir Bakış Açısı
}

\author{
Gülsüm SERTEL *, Süleyman KARATAŞ ${ }^{* *}$, Engin KARADAĞ $\breve{K}^{* * *}$
}

• Geliş Tarihi: 16.10.2021 • Kabul Tarihi: 18.12.2021 • Çevrimiçi Yayın Tarihi: 18.12.2021

\section{$\ddot{\mathbf{O} z}$}

$\mathrm{Bu}$ araştırmada, eğitim kurumlarında yönetim anlayışının, bürokratik yapının ve kültürel değerlerin yönetim süreçleri üzerindeki etkisini ortaya koymak amaçlandı. Araştırmada nicel araştırma yöntemlerinden korelasyonel desen kullanıldı. Araştırmanın örneklemini Denizli ili Pamukkale ve Merkezefendi ilçelerinde bulunan resmi eğitim kurumlarında görev yapan öğretmenler arasından tabakalı örnekleme yöntemiyle seçilen 418 öğretmenden oluşturdu. Verilerin toplanmasında "Yönetim Süreçlerinin Etkililiğì", "Yönetim Anlayışları", "Okul Yapısının Etkililiğì” ve "Bireysel Kültürel Değerler” ölçekleri kullanıldı. Araştırma sonucunda; Pozitivist yönetim anlayışı ve kolaylaştırıcı bürokrasi ile yüksek düzeyde pozitif ilişkili; engelleyici bürokrasi ile orta düzeyde negatif ilişkili; kaotik yönetim anlayışı ve belirsizlikten kaçınma ile düşük düzeyde pozitif ilişkili olduğu görüldü. Çoklu hiyerarşik regresyon analizi sonucunda, kolaylaştırıcı bürokratik yapının, pozitivist yönetim anlayışının ve uzun verimlilik kültürel değerinin yönetim süreçleri üzerinde yüksek düzeyde etkiye sahip olduğu görüldü. Geleceğe yönelik uzun vadeli planlama, kolaylaştırıcı bürokratik yapı, pozitivist ve post modern felsefenin iç içe geçtiği bir yönetim anlayışıyla yönetim süreçlerinin etkililiği sağlanabilecektir. Yönetim süreçlerinde etkili olabilecek diğer faktörlerin farklı yöntemler kullanılarak incelenmesi gerekmektedir.

Anahtar sözcükler: Yönetim süreçlerinin etkililiği, yönetim anlayışı, bürokratik yapı, kültürel değerler

Atıf:

Sertel, G., Karataş, S. ve Karadă̆, E. (2022). Yönetim süreçlerinin etkililiğinin incelenmesi: Yönetim anlayışı, bürokratik yapı ve kültürel değerler bağlamında çoklu ve bütüncül bir bakış açısı. Pamukkale Üniversitesi Eğitim Fakültesi Dergisi, 55, 72-99. doi:10.9779.pauefd.1010888

\footnotetext{
* Doktora Öğrencisi, Akdeniz Üniversitesi / Milli Eğitim Bakanlığı, Antalya, Türkiye, gulsum_sertel@hotmail.com, ORCID ID: 0000-0002-1907-040X

** Doç. Dr., Akdeniz Üniversitesi, Antalya, Türkiye, skaratas@akdeniz.edu.tr, ORCID ID: 0000-0003-0002-2886 (Sorumlu Yazar)

*** Prof. Dr., Akdeniz Üniversitesi, Antalya, Türkiye, enginkaradag@akdeniz.edu.tr, ORCID ID: 0000-0002-9723-3833
} 


\section{Giriş}

Günümüzde teknolojideki, ekonomideki, siyasetteki, iletişimdeki, sosyo-kültürel değerlerdeki ani ve büyük değişimler yönetsel rolleri, iş ve süreçlerini etkilemektedir (Dess ve Picken, 2000). Küreselleşme ile birlikte demografik kalıplarda meydana gelen değişimler, ulusal ve küresel düzeydeki farklı değerlere, inançlara ve beklentilere sahip insanların yönetilmesi ve yönetim iş ve süreçlerinin doğasına etki eden unsurları anlamanın gerekliliğini daha da artırmaktadır. Liderlik algısının ve yönetim anlayışının da paradigmalara bağlı olarak değiştiği örgütlerin, geleneksel yapılardan, çağın gereklerine uygun karmaşık ve esnek yapılara doğru evrilmesi (Palmberg, 2009), yöneticilerin yönetim anlayışlarının dayandığı felsefeyi, onların yönetsel uygulamalarının bürokratik yapıdaki yansımalarını ve yönetim süreç ve çıktıları üzerindeki etkisini incelemeyi de gerekli kılmaktadır. Dolayısıyla örgütlerde, yapı, bireyler, kültürel değerler, politik uygulamalar ve yönetim anlayışı çalışanların performansını etkilemede kaldıraç noktalarını temsil ederken (Hoy ve Miskel, 2010), yönetim süreçlerinin işleyişini de etkilemektedir. Bu çerçevede mevcut araştırmada, genelde örgütlerde özelde okullarda yönetim anlayışının, bürokratik yapının ve kültürel değerlerin yönetim süreçleri üzerindeki etkisi incelenmiştir.

\section{Yönetim Süreçlerinin Etkililiği}

Yönetim, insanlar ve kaynaklar aracılığıyla etkili ve verimli bir şekilde örgütsel amaçlara ulaşma sürecidir (Aydın, 2018; Bateman ve Snell, 2013; Bursalığlu, 2015; Robbins, Decenzo ve Coulter, 2013). Yönetim süreci de amaçlar doğrultusunda bir akışı, değişimi ve oluşu içinde barındıran, örgütü dönüştürme, işletme, yaşatma ve geliştirme işlevlerinin yerine getirildiği bir süreçtir (Başaran, 2008; Bursalığlu, 2015). Kısacası yönetim süreci, örgüt amaçlarının etkili ve verimli bir şekilde yerine getirilmesinde sistemli, bilinçli ve organize bir biçimde gerçekleştirilen kapsamlı ve çok yönlü faaliyetler bütünüdür.

Yönetim süreçleri ilk defa H. Fayol tarafından bilimsel olarak ele alınmış; planlama, örgütleme, emir verme, koordinasyon ve kontrol olarak sınıflandırılmıştır (Fayol, 1916). Gregg (1957) tarafından karar verme, planlama, örgütleme, iletişim, etki, eşgüdüm ve değerlendirme olarak yapılan sınıflandırmada, yönetim süreçleri birbirleriyle ilişkili olan yedi öğeden oluşan bir eylemler bütünü olarak nitelendirilmiştir. Alanyazın incelendiğinde yönetim süreçlerini oluşturan öğelerin birbiriyle ilişkili olduğu ve bütünlük gösterdiği belirtilmektedir (Akyol, 2013; Aydın, 2018; Erdoğan, 2003). Aydın'a (2018) göre yönetim süreçlerini oluşturan bileşenlerden hiçbiri tek başına bir anlam ifade etmez, bütünlük gösterir 
ve aralarında organik bir bağ vardır. Bu bağlamda, eğitim alanında yönetim süreçlerini bir bütün olarak ele alan çalışmaların oldukça az olduğu ve belirli konularda ele alındığ1 görülmektedir. Bu çalışmalarda yönetim süreçlerinin, örgütsel adalet (Akyol, 2013; Aç1l, 2020); yönetim süreçlerinin işleyişi (Aydın, 2019; Aydoğan, 1988; Büte ve Balc1, 2010); ölçek geliştirme (Gül, 2017); duygu yönetimi (Çoruk, 2012); yöneticilerin duygusal, sosyal ve ruhsal yeterlilikleri (Summak ve Yazgan, 2007) gibi değişkenlerle ele alındığ görülmektedir. Yapılan çalışmalardan hareketle, eğitim alanında yönetim süreçlerine etki eden değişkenlerin araştırılması, yönetsel ve örgütsel etkililik, liderlik ve örgütsel davranış gibi alanlardaki önemi bakımından yadsınamaz bir gerçek olarak görülmektedir.

\section{Bürokratik Yapı ve Yönetim Süreçleri}

Örgüt yapısı, örgütteki iş bölümü ve koordinasyon arasındaki yolların toplamı olup (Mintzberg, 2014), tüm faaliyetlerinin biçimini, işleyişini ve uyumunu etkilemektedir (Griffin ve Moorhead, 2014). Dolayısıyla, yönetim süreçlerinin işleyişis üzerinde etkili olan unsurlardan biri de örgütlerin bürokratik yapılarıdır. Okullar, bürokratik yapı özelliklerinin birçoğuna sahip olan formal örgütlerdir (Buluç, 2009; Hoy ve Miskel, 2010; Messick, 2012). Bürokratik yapının okullardaki örgütsel ve yönetsel davranışı analiz etmedeki önemi birçok araştırmacı tarafından araştııılmıştır (Abbott, 1965; Abbott ve Caracheo, 1988; Corwin ve Borman, 1988; Firestone ve Herriot, 1981; Miles, 1965). Abbott (1965) okul örgütünü, yüksek düzeyde gelişmiş bürokrasi olarak nitelendirmektedir. Hoy ve Sweetland (2000,2001) eğitim örgütlerini, merkezileşme (yetkinin kademeleştirilmesi) ve biçimlendirme (kurallar, düzenlemeler, prosedürler vb.) temelinde yetkilendirici ve engelleyici özellik göstermelerine göre "kolaylaştırıcı (yetkilendirici) bürokratik yapı" ve "engelleyici bürokratik yapı" olarak ele almıştır.

Okullara yönelik yapılan araştırmalar, okulların yapısal özelliklerinin birbirinden farklılaştığını göstermekle birlikte (Hoy, 2003; Hoy ve Miskel, 2010; Hoy ve Sweetland, 2000,2001; Sinden vd.,2004), okullarda engelleyici bir yapının aksine kolaylaştırıcı bir okul yapısının oluşturulmasını gerekli kılmaktadır (Hoy ve Sweetland, 2001). Çünkü okulların kolaylaştırıcı bürokratik yapısı, öğretmenler arası meslektaş iş birliğini olumlu etkilemekte ve akademik başarıya katkı sağlamaktadır (Weick ve Sutcliffe, 2001). Ayrıca kolaylaştırıcı okul yapısında yönetici ve öğretmenler iş birliği içinde hareket etmekte, sorunların çözümüne yönelik birlikte karar vermekte, yönetim öğretmenlerin daha etkili görev yapabilecekleri yapıları desteklemektedir (Wu, Hoy ve Tarter, 2013). Dolayısıla öğretmenler tarafından algılanan bürokratik yapının hem onların okula yönelik tutum ve 
davranışlarını etkilediği hem de yönetim süreçlerini etkileyen önemli faktörlerden biri olduğu görülmektedir.

\section{Yönetim Anlayışı ve Yönetim Süreçleri}

Örgütlerde, yöneticilerin insanın doğasına yönelik varsayımları, insana bakış açıları, onların yönetime dair iş ve işleyişs süreçlerinin bir belirleyicisidir (Aydın, 2018). Yaygın kuramsal yaklaşıma dayalı olarak bu çalışmada okul yöneticilerinin yönetim anlayışı pozitivist ve postmodern yönetim anlayışı açısından ele alındı. Pozitivist yönetim anlayışında çalışan uyum ve itaat gösteren, kurallara göre hareket eden, planlı-programlı olarak düzenlenmiş bir hiyerarşinin parçası olan, insiyatif verilmeyen, informal ilişki kurması yasak olan örgütsel bir varlık olarak görülmektedir (Bulaç, 1990). Pozitivist yönetim anlayışında yönetici ise, lider değildir, başarısını otoritesine borçlu olup, emir vermekte, itaat istemekte, statükoyu korumak için enerjisini sürekli olarak bozulan dengeyi yeniden sağlamaya çalışmakla geçirmektedir (Açıkalın, 1995). Pozitivist yönetim anlayışına sahip okullarda yetki ve güç yöneticide toplanmakta; okul yöneticisi kendisine verilen bu gücü, sistemli kurallardan oluşan bürokratik ve merkezi bir baskı aracı olarak kullanmakta; bireylerin değer, inanç, beklenti ve seçimleri göz ardı edilmektedir (Aslanargun, 2007). Bütün bu özellikler dikkate alındığında, yapısalcı ve bürokratik eğilim gösteren pozitivist yönetim anlayışı, amaç merkezli, rasyonel karar alma süreci, yapıyı her şeyin üstünde tutma, hiyerarşinin üst yönetimde toplanması ve grup içinde bireyin ihmal edilmesi bakımından eleştirilmektedir (Bush, 1995). Dolayısıyla pozitivist modern yönetim anlayışının bireysel değerlerin ihmal edilmesi yönünün sorgulanmasına ve eksikliklerine yönelik yapılan eleştiriler postmodern yönetim anlayışının doğmasına zemin hazırlamıştır.

Postmodern anlayışın yönetime olan en önemli katkılardan birisi “yönetici, müdür” gibi pozitivist anlayışın uzantıları olarak görülen kavramların yerine "liderlik" olgusunu ön plana çıkarmasıdır. Postmodern yönetim anlayışının hâkim olduğu okullarda, lider olan okul yöneticisi, uzun vadeli düşünmekte, olaylara eleştirel ve şüpheci bakabilmekte, insani değerleri ön planda tutarak motivasyon gibi rasyonel olmayan süreçlere yönelmektedir (Aslanargun, 2007). Hem pozitivist (klasik) yönetim anlayışının hem de postmodern (kaos) yönetim anlayışının iç içe geçtiği gerçeğinden hareketle, günümüzde gelişmişlik, büyüklük ve karmaşıklık özelliklerine sahip olan çağdaş örgütlerin yöneticilerinin de bu karmaşayı ve kaosu yönetme becerisine sahip olmaları gerektiği kaçınılmaz bir gerçek olarak karşımıza çıkmaktadır (Demirtaş, 2006). Dolayısıyla okullarda yöneticilerin yönetim anlayışının 
incelenmesinin yönetim süreçlerinin işleyişinde ve örgütün insana ve topluma bakış açısının örgütsel çıktılar üzerinde etkili olduğu düşünülmektedir.

\section{Kültürel Değerler ve Yönetim Süreçleri}

En genel anlamıyla kültür, bir grubu diğerlerinden ayırt eden ve grup tarafindan paylaşılan anlamlar sistemidir (Aydın, 2018; Robbins, 1998). Hofstede tarafından kültür, yaşam boyunca kazanılan, bir toplumun üyelerini diğerlerinden ayırt eden, toplumun çevresi ile ilişkilerini etkileyen, genel karakteristik özelliklerinin etkileşiminden oluşan, kolektif bir zihin programlaması olarak nitelendirmektedir (Hofsede, 1980a, 1980b, 2001; Hofstede, Hofstede ve Minkov, 2010). Araştırmacı kültürün, bireylerin içinde yaşadıkları ulusun ortak kültürel bileşenlerinden oluştuğunu ve farklı ülkelerdeki insanların farklı kültürel değerlere sahip olduğunu vurgulamakta, bu farklılıkları ulusal kültür olarak kavramsallaştırmaktadır (Hofstede, 2001). Bu araştırmada eğitim kurumlarının kültürel değerleri, Hofstede'nin kültürel değerler teorisinin güç mesafesi, belirsizlikten kaçınma, bireycilik/toplulukçuluk (kolektivist), erillik/dişillik (Hofstede, 1980a) ve kısa/uzun vadeli erimlilik (Hofstede ve Bond, 1988; Hofstede, vd.,2010; Hofstede, 2001) boyutları açısından incelenmiştir.

Güç mesafesi, genellikle gücün toplumdaki dağılımının uygunluğuna yönelik inanç olup (Steers, Sanchez-Runde Nardon, 2010), örgüt ve kurumlarda güç ve statünün eşit dağılmadığının kabul edilme derecesidir (Hofstede, 1980a; Yukl, 2013). Belirsizlikten kaçınma, bireylerin belirsiz veya bilinmeyen durumlar karşısında hissettiği tehdit ve endişenin düzeyi ile ilgilidir (Hofstede, 2001). Bireyci kültürlerde, bireyler "ben" duygusuyla hareket eder, bireysel ihtiyaçlar, menfaatler ve özerklik ön plandadır, kişisel haklar sosyal sorumluluklardan daha önemlidir (Dickson vd.,2003; Gelfand, Bhawuk, Nishi ve Bechtold, 2004; Hofstede, 1980b; Scarborough, 1998; Steers vd.,2010). Toplulukçu (kolektivist) kültürlerde, grubun menfaatleri bireysel menfaatlerden önceliklidir (Kluckhohn ve Strodtbeck, 1961; Steers vd.,2010; Triandis, 1995), gruba bağlılık bireyin öz kimliğinin önemli bir unsurudur ve gruba sadakat önemli bir değerdir (Yukl, 2013) ve bireyler "biz" duygusuyla hareket eder (Hofstede, 1980b). Eril kültürlerde bireyler iddialı, hırslı, rekabetçi, mal varlığı ve paraya önem veren, bireysel ve maddi başarı odaklıdır (Hofstede, 1980a). Dişil kültürlerde ise bireyler daha mütevazı ve hassas olup, güçlü sosyal bağlar, yaşam kalitesi ve diğerlerinin zenginliği değerlidir (Hofstede, 1980a, 2001). Uzun/klsa vadeli erimlilik, zaman, hedef, planlama, iş, yaşam ve ilişkilere bakış açısıyla ilgili olup; uzun vadeli erimli kültürlerde, gelecek yönelimi, kendini adama, çalışkanlık ve tasarruf değer 
görürken; kısa vadeli erimli kültürlerde ise geçmiş ve şimdiki zaman yönelimi, gelenekler ve toplumsal sorumluluklar değer görür (Hofstede vd.,2010; Steers vd.,2010).

Kültürel değerler toplum içinde yer alan farklı yapılardaki örgütlerin kültürünün, bu örgütler içindeki farklı kültürel değerlere sahip bireylerin ve olayların anlaşılmasına (Hofstede, 1983), örgütlerde amaç ve hedefler, karar verme, yapı ve etkili motivasyon araçlarının biçimlendirilmesine önemli katkılar sağlamaktadır (Hofstede, 1981). Eğitim kurumlarında yöneticilerin, kültürel değerlerin farkında olması ve bunları örgütün amaçları doğrultusunda etkili bir motivasyon kaynağına dönüştürmesi hem yönetim süreçlerinin etkililiğini hem de örgütsel etkililiği artıracaktır.

\section{Araştırmanın Amacı}

$\mathrm{Bu}$ bağlamda araştırmanın amacı, Millî Eğitim Bakanlığı'na bağlı resmi eğitim kurumlarında görev yapan öğretmenlere göre, okul yöneticilerinin yönetim anlayışının, okulların bürokratik yapısının ve okuldaki kültürel değerlerin yönetim süreçleri ile ilişkisini ortaya koymaktır. Yapılan literatür taraması ve araştırmanın amacı kapsamında aşağıdaki hipotezler test edilmiştir:

$\mathrm{H}_{1}$ : Kolaylaştırıcı bürokrasi yönetim süreçlerinin etkililiği üzerinde pozitif etkiye, engelleyici bürokrasi ise yönetim süreçlerinin etkililiği üzerinde negatif etkiye sahiptir.

$\mathrm{H}_{2}$ : Yönetim anlayışı ile yönetim süreçlerinin etkililiği arasında anlamlı bir ilişki vardır.

$\mathrm{H}_{3}$ : Kültürel değerler ile yönetim süreçlerinin etkililiği arasında anlamlı bir ilişki vardır.

$\mathrm{H}_{4}$ : Öğretmenlere ve okullara ait demografik değişkenler kontrol altına alındığında, yönetim anlayışı, kültürel değerler ve kolaylaştırıcı okul yapısı, yönetim süreçlerini yüksek düzeyde etkilemektedir.

\section{Yöntem}

\section{Araştırmanın Modeli}

Yönetim süreçlerinin etkililiği, yönetim anlayışı, bürokratik yapı ve kültürel değerler arasındaki ilişkiyi inceleyen bu nicel araştırmada korelasyonel desen kullanıldı. Korelasyonel desen, iki ya da daha fazla sayıdaki değişken arasındaki ilişki olup olmadığını ve/veya ilişkinin derecesini belirlemeyi amaçlayan araştırma desenidir (Fraenkel ve Wallen, 2006; Karasar, 2017). 


\section{Evren ve Örneklem}

Bu araştırmanın evrenini Denizli İli Milli Eğitim Müdürlüğü Strateji Geliştirme Biriminden alınan verilere göre 2019-2020 öğretim yılında Pamukkale ve Merkezefendi ilçelerinde bulunan toplam 265 resmi eğitim kurumunda görev yapan 7698 öğretmen oluşturmaktadır. Araştırmada genel kabul gören \%95 güven düzeyi ve \%5'lik hata payı dikkate alınarak yeterli minimum örneklem büyüklüğü 366 olarak hesaplandı (Field, 2009). Ancak 500 öğretmene dağıtılan ölçek formundan geri dönen 462 ölçekten hatalı ve eksik kodlanan ölçekler çıkarıldıktan sonra kalan 418 ölçek çalışmanın örneklemini oluşturdu. Örneklem büyüklüğünün hesaplanmasında olasılıklı örnekleme tekniklerinden tabakalı örnekleme tekniği kullanıldı. Tabakalama yapılırken okul türleri (ilkokul-ortaokul-lise) dikkate alındı. Tabakalı örnekleme yöntemiyle homojen olmayan araştırma evreninde yer alan alt grupların evren içindeki oranı bulunarak (Büyüköztürk, Çakmak, Akgün, Karadeniz ve Demirel, 2008) alt grupların evreni temsil etme yeteneğinin artması sağlandı (Balcı, 2018).

Araştırmaya katılan öğretmenlerin \%67.7'si kadın, \%32.3'ü erkek; \%84.2'si lisans mezunu, \%15.8'i yüksek lisans mezunudur. Ayrıca öğretmenlerin \%8.4'ü 5 yıl ve altı, \%16.7'si 6-10 yıl, \%20.6's1 11-15 y1l, \%27.8'i 16-20 y1l, \%13.4'ü 21-25 yıl ve \%13.2'si 26 yıl ve üzeri kıdeme sahiptir. Ve öğretmenlerin \%24.6'sı temel eğitim, \%37.8'i sözel, \%19.6'sı sayısal, \%6.7'si mesleki-teknik ve \%11.2'si sanat-spor branşındadır. Araştırmadaki okulların \%25.8'i ilkokul, \%43.5'i ortaokul ve \%30.6'sı lisedir. Ayrıca okulların \%25.6's1 düşük, \%60.5'i orta ve \%13.9'u yüksek sosyo-ekonomik düzeydedir. Okulların \%28.5'inde 1-20 öğretmen, \%19.6'sında 21-40 öğretmen ve \%51.9'unda 41 ve üzerinde öğretmen görev yapmaktadır. Ayrıca okulların \%7.7'sinde 1 yönetici, \%29.4'ünde 2 yönetici, \%20.8'inde 3 yönetici ve \%42.1'inde 4 ve daha fazla yönetici bulunmaktadır.

\section{Veri Toplama Araçları}

Araştırmanın verileri, her biri aşağıdaki gibi tanıtılan çeşitli ölçekler kullanılarak toplanmıştır:

\section{Yönetim anlayışları ölçeği}

Yönetim anlayışının ölçülmesinde, Usta (2017) tarafından geliştirilen, 2 boyutlu (kaotik yönetim anlayışı ve pozitivist yönetim anlayışı) ve 23 maddeli "Yönetim Anlayışları Ölçeği" kullanıld1. Usta (2017) tarafından ölçeğin güvenirlik katsayısı( $\alpha$ ).948 (alt boyutlarda sırasıyla.970 ve .888) olarak tespit edilmiştir. Ölçek 5'li likert tipindedir. Bu çalışmada 
ölçeğe ait Barlett Küresellik Testi sonucu anlaml1, Kaiser-Meyer-Olkin (KMO) değeri.960, güvenirlik katsayıs1.984 (alt boyutlarda sırasıyla.982 ve.943) olarak hesaplandı.

\section{Kolaylaştırıcı okul yapısı ölçeği}

Hoy ve Sweetland (2000) tarafından geliştirilen, Buluç (2009) tarafından Türkçe'ye uyarlanan, psikometrik özellikleri Özer ve Dönmez (2013) tarafından yeniden incelenen, 2 boyutlu (kolaylaştırıcı bürokrasi ve engelleyici bürokrasi) ve 12 maddeli "Kolaylaştırıcı Okul Yapısı Ölçeği” kullanıldı. Özer ve Dönmez (2013) ölçeğin güvenirlik katsayısını( $\alpha$ ) “Kolaylaştırıcı Bürokrasi” alt boyutu için.774 ve "Engelleyici Bürokrasi” alt boyutu için.806 olarak tespit edilmiştir. Ölçek 5'li likert tipindedir. Bu çalışmada ölçeğe ait Barlett Küresellik Testi sonucu anlamlı, Kaiser-Meyer-Olkin (KMO) değeri.834; güvenirlik katsayısı "Kolaylaştırıcı Bürokrasi” alt boyutu için.833 ve "Engelleyici Bürokrasi” alt boyutu için.883 olarak hesapland1.

\section{Bireysel kültürel değerler ölçeği}

Araştırmada toplumsal düzeydeki kültürel değerleri belirleyebilmek amacıyla Hofstede tarafindan geliştirilen (Kültürel Değerler Ölçeği), Yoo, Donthu ve Lenartowicz (2011) tarafından bireysel bağlamda yeniden ele alınan; Saylık (2019) tarafından Türkçe’ye uyarlan “Bireysel Kültürel Değerler Ölçeği” kullanıldı. 5 alt boyut (güç mesafesi, belirsizlikten kaçınma, kolektivizm, uzun erimlilik, erillik) ve 26 madde olan ölçek 5'li likert tipindedir. Saylık (2019) ölçeğin güvenirlik katsayısını( $\alpha$ ).80 (alt boyutlar sırasıyla.63,.82,.87,.85 ve.82) olarak tespit etmiştir. Bu çalışmada ölçeğe ait Barlett Küresellik Testi sonucu anlaml1, Kaiser-Meyer-Olkin (KMO) değeri.833; güvenirlik katsayıs1.858 (alt boyutlar sirasiyla $.883, .856, .845, .879, .838$ ve.881) olarak hesaplandı.

\section{Yönetim süreçlerinin etkililiği ölçĕgi}

Okul yöneticilerinin yönetim süreçlerini ne kadar etkili kullandıklarını ölçmek amacıyla Gül (2017) tarafından geliştirilen, tek boyutlu ve 35 maddeli "Yönetim Süreçlerinin Etkililiği Ölçeği”” kullanıldı. Gül (2017) tarafından ölçeğin güvenirlik katsayısı( $\alpha$ ).982 olarak tespit edilmiştir. Ölçek 5'li likert tipindedir. Bu çalışmada ölçeğe ait Barlett Küresellik Testi sonucu anlamlı, Kaiser-Meyer-Olkin (KMO) değeri.974, güvenirlik katsayısı.992 olarak hesapland1. 


\section{Verilerin Toplanması ve Analizi}

Araştırmada kullanılan ölçekler çoğaltıldı, okullara gidilerek yüz yüze öğretmenlere dağıtıldı. Toplanan veriler SPSS 23.0 paket programı kullanılarak analiz edildi. Öncelikle verilerin normallik dağılımı için normallik analizi yapıldı. Bu araştırmada, verilerin çarpıklık değerleri “-1.175” ile “0.817” ve basıklık değerleri “-.867” ile “1.408” arasındadır. Araştırmadaki verilerin çarpıklık ve basıklık değerlerinin $\pm 1,5$ arasında kaldı $\breve{g} 1$ ve verilerin normal dağıldığg görüldü (Tabachnick ve Fidell, 2013) ve verilerin analizinde parametrik testler kullanıldı. Toplanan verilerin güvenirliği Cronbach's Alpha iç tutarlılık katsayısıyla, demografik değişkenler yüzde ve frekans analiziyle, değişkenlerin aritmetik ortalama ve standart sapma değeri betimsel istatistiklerle, değişkenler arasındaki ilişkinin yönü ve düzeyi ise pearson korelasyon analizi kullanılarak incelendi. Korelayon katsayısının mutlak değeri 0.70-1.00 "yüksek"; 0.70-0.30 “orta"; 0.30-0.00 ise "düşük" düzeyde bir ilişki olduğu şeklinde yorumlandı (Büyüköztürk, 2016; Roscoe, 1975). Araştırmada aynı anda ve sırasıyla hem kategorik hem de sürekli değişkenlerin etkisini birlikte inceleyebilmek ve oluşturulan son modelde etkisi görülen nihai değişkenlerin birlikte etkisini görebilmek için bağımsız değişkenlerin (yönetim anlayışı, okul yapısı, kültürel değerler), bağımlı değişkene (yönetim süreçlerinin etkililiği) olan etkisi çoklu hiyerarşik regresyon analizi ile incelendi.

Analiz kapsamında oluşturulan modellerde çoklu doğrusallık varsayımının sağlanıp sağlanmadığını tespit etmek amacıyla doğrudaşlık/eş doğrusallık (collinearity statistics) değerlerine bakıldı. Araştırmada tolerans değerlerinin “.18”den büyük ve VIF değerlerinin de "5.33"den küçük olduğu görüldü. Elde edilen tolerans değerlerinin 0.10 'dan büyük olduğu (Çokluk, Şekercioğlu ve Büyüköztürk, 2018; Field, 2009; Mertler ve Vannatta, 2005) ve VIF (Varyans artış faktörü-Variance Inflation Factor) değerlerinin 10'a eşit veya daha büyük olmadığı (Webster, 1992 akt.Albayrak, 2005) (Tolerans=1/VIF, Tolerans $>1-R^{2}$ ); bağımsız değişkenler arasında çoklu doğrusal bağlantı olmadığı ve standardize edilmemiş beta(B) katsayılarının (Unstandardized Coefficients) regresyon modeline ait denklemlerde kullanılmasının uygun olduğu tespit edildi.

Çoklu hiyerarşik regresyon analizinde, öğretmenlerin ve okulların özelliklerine yönelik kategorik değişkenler "dummy (yapay/kukla) değişken” olarak dönüştürüldükten sonra analize dâhil edildi. Dummy değişkenlerden öğretmenlere ilişkin cinsiyet $=$ erkek1; eğitim durumu=lisans1; branş=temel eğitim1"; kıdem=1-5yıl ve okula ilişkin okul türü=ilkokul1; öğretmen sayısı=1-20öğretmen; yönetici sayısı=yönetici1; sosyo-ekonomik düzey=düşük1olarak kodlandı. Öncelikle birinci modele öğretmen özellikleri ve ikinci 
modele okul özellikleri dahil edilerek kategorik (dummy) değişkenler kontrol altına alındıktan sonra, üçüncü modele okul yapısı, dördüncü modele yönetim anlayışı, beşinci modele bireysel kültürel değerler enter yöntemi ile analize dahil edildi. Modellerde anlamlı etkisi görülen değişkenlerin nihai etkisini görmek amacıyla altıncı modelde etkisi bulunan değişkenler birlikte analize dahil edildi. Analiz sonuçları beta değeri( $\beta)$ yerine düzeltilmemiş beta(B) değeri üzerinden yorumlandı.

Analizdeki regresyon katsayıları etki büyüklüğünü gösteren istatistikler olmakla birlikte, çoklu model analizinde etki büyüklüğünün (effect size) hesaplanmasında Aiken ve West (1991) tarafindan önerilen Cohen'in $f^{2}=\left(\mathrm{r}_{2}^{2}-\mathrm{r}_{1}^{2}\right) /\left(1-\mathrm{r}_{1}^{2}\right)$ formülü kullanıldı. Bu denklemde $r_{1}^{2}$, hiyerarşik regresyon analizinde ikinci adıma ait $R^{2}$ (R square); $r_{2}^{2}$ ise üçüncü adıma ait $\mathrm{R}^{2}$ ( $\mathrm{R}$ square) değeridir. Formüle göre, $f^{2}=0,02$ ise düşük etki; $f^{2}=0,15$ ise orta etki; $f^{2}=0,26$ ise büyük etki olduğunu göstermektedir (Cohen, Cohen, West ve Aiken, 2003).

\section{Bulgular}

\section{Betimsel istatistiklere ve korelasyona ilişkin bulgular}

Araştırmadaki değişkenlere ait betimsel istatistikler ile değişkenler arasındaki ilişkilerin yönünü ve düzeyini gösteren korelasyon matrisi değerleri Tablo 1'de verildi.

Tablo 1'de yer alan ortalama değerleri incelendiğinde, öğretmenlerin yönetim anlayışlarına göre, pozitivist yönetim anlayışının yüksek, kaotik yönetim anlayışının orta düzeyde olduğu görüldü. Bireysel kültürel değerlere göre ise, uzun erimliliğin çok yüksek, belirsizlikten kaçınma ve kolektivizmin yüksek, erilliğin orta ve güç mesafesinin düşük düzeyde algılandığı görüldü. Okul yapısının etkililiği açısından incelendiğinde öğretmenlerin yüksek düzeyde kolaylaştırıcı bürokrasi, düşük düzeyde engelleyici bürokrasi algısına sahip oldukları görüldü. Ayrıca öğretmenlerin yönetim süreçlerini yüksek düzeyde etkili olarak algıladıkları görüldü.

Korelasyon analizi sonucunda, yönetim süreçlerinin etkililiğinin yönetim anlayışının pozitivist yönetim boyutuyla pozitif yönlü ve yüksek düzeyde ilişkili olduğu görüldü. Yönetim süreçlerinin etkililiğinin bireysel kültürel değerlerin belirsizlikten kaçınma, kolektivizm, güç mesafesi ve uzun erimlilik boyutlarıyla pozitif yönlü ve düşük düzeyde ilişkili olduğu görüldü. Yönetim süreçlerinin etkililiğinin okul yapısının kolaylaştırıcı bürokrasi boyutuyla pozitif yönlü ve yüksek düzeyde, engelleyici bürokrasi boyutuyla negatif yönlü ve orta düzeyde ilişki olduğu görüldü. 
Tablo 1.Yönetim Anlayışı, Bireysel Kültürel Değerler, Okul Yapısı, Yönetim Süreçlerinin Etkililiği Değişkenlerine Ait Betimsel İstatistikler ve Korelasyon Matrisi(N=418)

\begin{tabular}{lcccccccccccc}
\hline & KY & PY & YA & GM & BK & K & UE & E & BKD & KB & EB & YSE \\
\hline KY & - & & & & & & & & & & & \\
PY & $.34^{* *}$ & - & & & & & & & & & & \\
YA & $.91^{* *}$ & $.33^{* *}$ & - & & & & & & & & & \\
GM & $.64^{* *}$ & $.11^{*}$ & $.54^{* *}$ & - & & & & & & & & \\
BK & $.66^{* *}$ & $.35^{* *}$ & $.60^{* *}$ & .09 & - & & & & & & & \\
K & $.79^{* *}$ & $.28^{* *}$ & $.76^{* *}$ & $.18^{* *}$ & $.43^{* *}$ & - & & & & & & \\
UE & $.31^{* *}$ & $.23^{* *}$ & $.48^{* *}$ & $-.20^{* *}$ & $.47^{* *}$ & $.44^{* *}$ & - & & & & & \\
E & $.21^{* *}$ & .02 & $.50^{* *}$ & $.32^{* *}$ & -.06 & $.13^{* *}$ & -.10 & - & & & & \\
BKD & $.91^{* *}$ & $.33^{* *}$ & $1.00^{* *}$ & $.54^{* *}$ & $.60^{* *}$ & $.76^{* *}$ & $.48^{* *}$ & $.50^{* *}$ & - & & & \\
KB & $.31^{* *}$ & $.76^{* *}$ & $.33^{* *}$ & $.13^{* *}$ & $.31^{* *}$ & $.23^{* *}$ & $.19^{* *}$ & $.12^{*}$ & $.33^{* *}$ & - & & \\
EB & -.01 & $-.43^{* *}$ & .06 & $.23^{* *}$ & $-.26^{* *}$ & -.05 & $-.21^{* *}$ & $.35^{* *}$ & .06 & $-.47^{* *}$ & - & \\
YSE &. $\mathbf{3 0}$ & $.86^{* *}$ & $.28^{* *}$ &. $\mathbf{1 6} *$ & $.25^{* *}$ &. $\mathbf{2 2 ^ { * * }}$ & $\mathbf{. 1 2}$ & .08 & $.28^{* *}$ &. $\mathbf{7 9}$ & $\mathbf{- . 4 3}$ & - \\
$\overline{\boldsymbol{X}}$ & 3.25 & 3.78 & 3.85 & 2.19 & 3.88 & 3.62 & 4.32 & 2.64 & 3.40 & 3.74 & 2.51 & 3.85 \\
Ss & .59 & .92 & .55 & .96 & .73 & .83 & .60 & 1.16 & .49 & .78 & .96 & .96 \\
\hline **p<.01 & $* p<.05$ & & & & & & & & & &
\end{tabular}

$\overline{\boldsymbol{X}}$ :Ortalama, Ss: Standart Sapma, KY-Kaotik Yönetim, PY-Pozitivist Yönetim, YA-Yönetim Anlayışı, GM-Güç Mesafesi, BK-Belirsizlikten Kaçınma, K-Kolektivizm, UE-Uzun Erimlilik, E-Erillik, BKD-Bireysel Kültürel Değerler, KB-Kolaylaştırıcı Bürokrasi, EB-Engelleyici Bürokrasi, YSE-Yönetim Süreçlerinin Etkililiği

Tablo 1'de yer alan ortalama değerleri incelendiğinde, öğretmenlerin yönetim anlayışlarına göre, pozitivist yönetim anlayışının yüksek, kaotik yönetim anlayışının orta düzeyde olduğu görüldü. Bireysel kültürel değerlere göre ise, uzun erimliliğin çok yüksek, belirsizlikten kaçınma ve kolektivizmin yüksek, erilliğin orta ve güç mesafesinin düşük düzeyde algılandığı görüldü. Okul yapısının etkililiği açısından incelendiğinde öğretmenlerin yüksek düzeyde kolaylaştırıcı bürokrasi, düşük düzeyde engelleyici bürokrasi algısına sahip oldukları görüldü. Ayrıca öğretmenlerin yönetim süreçlerini yüksek düzeyde etkili olarak algıladıkları görüldü.

Korelasyon analizi sonucunda, yönetim süreçlerinin etkililiğinin yönetim anlayışının pozitivist yönetim boyutuyla pozitif yönlü ve yüksek düzeyde ilişkili olduğu görüldü. 
Yönetim süreçlerinin etkililiğinin bireysel kültürel değerlerin belirsizlikten kaçınma, kolektivizm, güç mesafesi ve uzun erimlilik boyutlarıyla pozitif yönlü ve düşük düzeyde ilişkili olduğu görüldü. Yönetim süreçlerinin etkililiğinin okul yapısının kolaylaştırıcı bürokrasi boyutuyla pozitif yönlü ve yüksek düzeyde, engelleyici bürokrasi boyutuyla negatif yönlü ve orta düzeyde ilişki olduğu görüldü.

Yönetim süreçlerinin etkililiğinin yordanmasını gösteren hiyerarşik çoklu regresyona ilişkin bulgular

Yönetim süreçlerinin etkililiğini yordayan bağımsız değişkenlerin etkisini belirlemek amacıyla yapılan çoklu hiyerarşik regresyon analizi sonuçları Tablo 2'de verildi.

Tablo 2.Yönetim Süreçlerinin Etkililiği Üzerinde Bă̆ımsız Değişkenlerin Etkisini Gösteren Hiyerarşik Çoklu Regresyon Analizi Sonuçları $(N=418)$

Yönetim Süreçlerinin Etkililiği

\begin{tabular}{|c|c|c|c|c|c|c|c|c|c|c|}
\hline \multirow{2}{*}{\multicolumn{2}{|c|}{$\begin{array}{c}\text { Yordayıcı } \\
\text { Değişkenler }\end{array}$}} & \multicolumn{3}{|c|}{ Model 1} & \multicolumn{3}{|c|}{ Model 2} & \multicolumn{3}{|c|}{ Model 3} \\
\hline & & $B$ & S.H. & $\beta$ & $B$ & S.H. & $\beta$ & $\boldsymbol{B}$ & S.H. & $\bar{\beta}$ \\
\hline \multirow{5}{*}{ 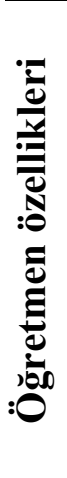 } & Sabit & 125.718 & 4.439 & & 125.660 & 4.619 & & 16.905 & 7.770 & \\
\hline & Erkek1 & -2.754 & 3.597 & -.038 & -3.967 & 3.650 & -.055 & -1.017 & 2.285 & -.014 \\
\hline & Lisans1 & $10.136 *$ & 4.524 & .110 & $10.849 *$ & 4.598 & .117 & 5.390 & 2.880 & .058 \\
\hline & $\begin{array}{l}\text { Temel } \\
\text { eğitim1 }\end{array}$ & 2.556 & 3.869 & .033 & 20.016 & 11.039 & .256 & -.079 & 7.067 & -.001 \\
\hline & $\begin{array}{l}1-5 y 11 \\
\text { k1dem }\end{array}$ & 7.387 & 6.058 & .061 & 11.925 & 6.563 & .098 & -3.851 & 4.114 & -.032 \\
\hline \multirow{5}{*}{ 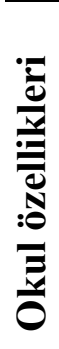 } & İlkokul1 & & & & -15.402 & 11.084 & -.200 & 3.542 & 7.044 & .046 \\
\hline & $\begin{array}{l}\text { Düşük } \\
\text { SED }\end{array}$ & & & & 3.161 & 4.235 & .041 & 2.173 & 2.625 & .028 \\
\hline & $1-20$ & & & & -5.463 & 5.776 & -.073 & -6.737 & 3.588 & -.090 \\
\hline & öğretmen & & & & & & & & & \\
\hline & 1 yönetici & & & & -1.403 & 6.534 & -.011 & 2.900 & 4.072 & .023 \\
\hline \multirow[b]{2}{*}{$\infty$} & KB & & & & & & & $5.402 * * *$ & .253 & .748 \\
\hline & $\mathrm{EB}$ & & & & & & & $-.485^{*}$ & .211 & -.083 \\
\hline \multirow{2}{*}{ 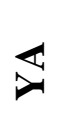 } & $\mathrm{KY}$ & & & & & & & & & \\
\hline & PY & & & & & & & & & \\
\hline
\end{tabular}




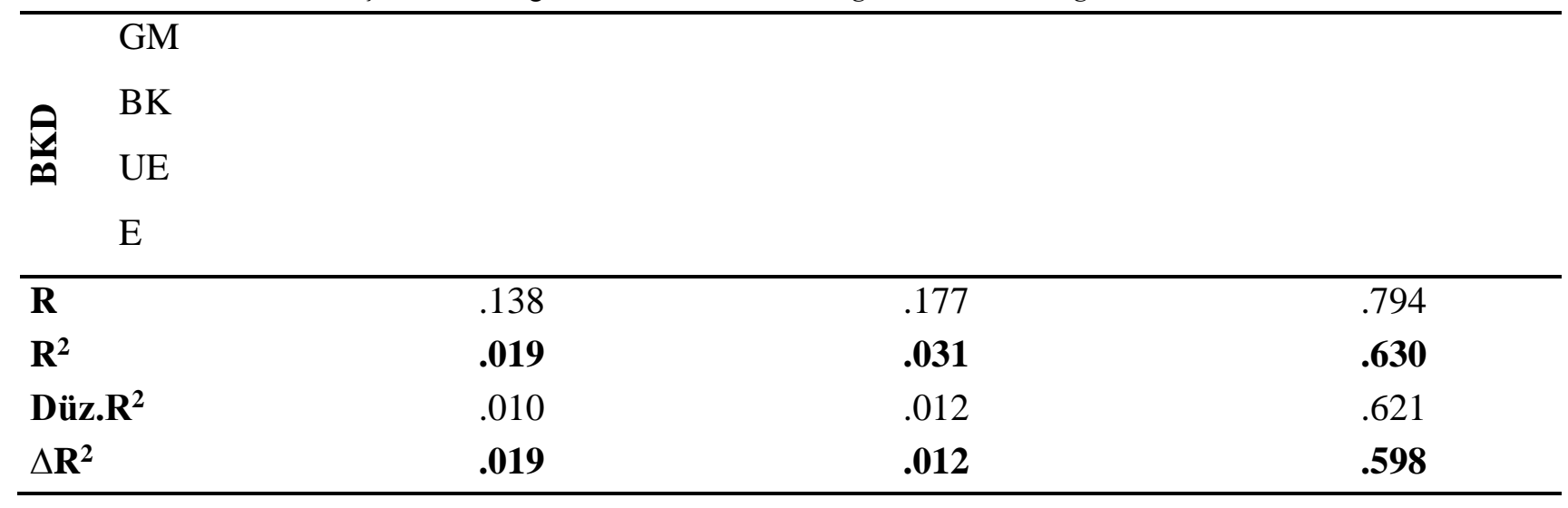

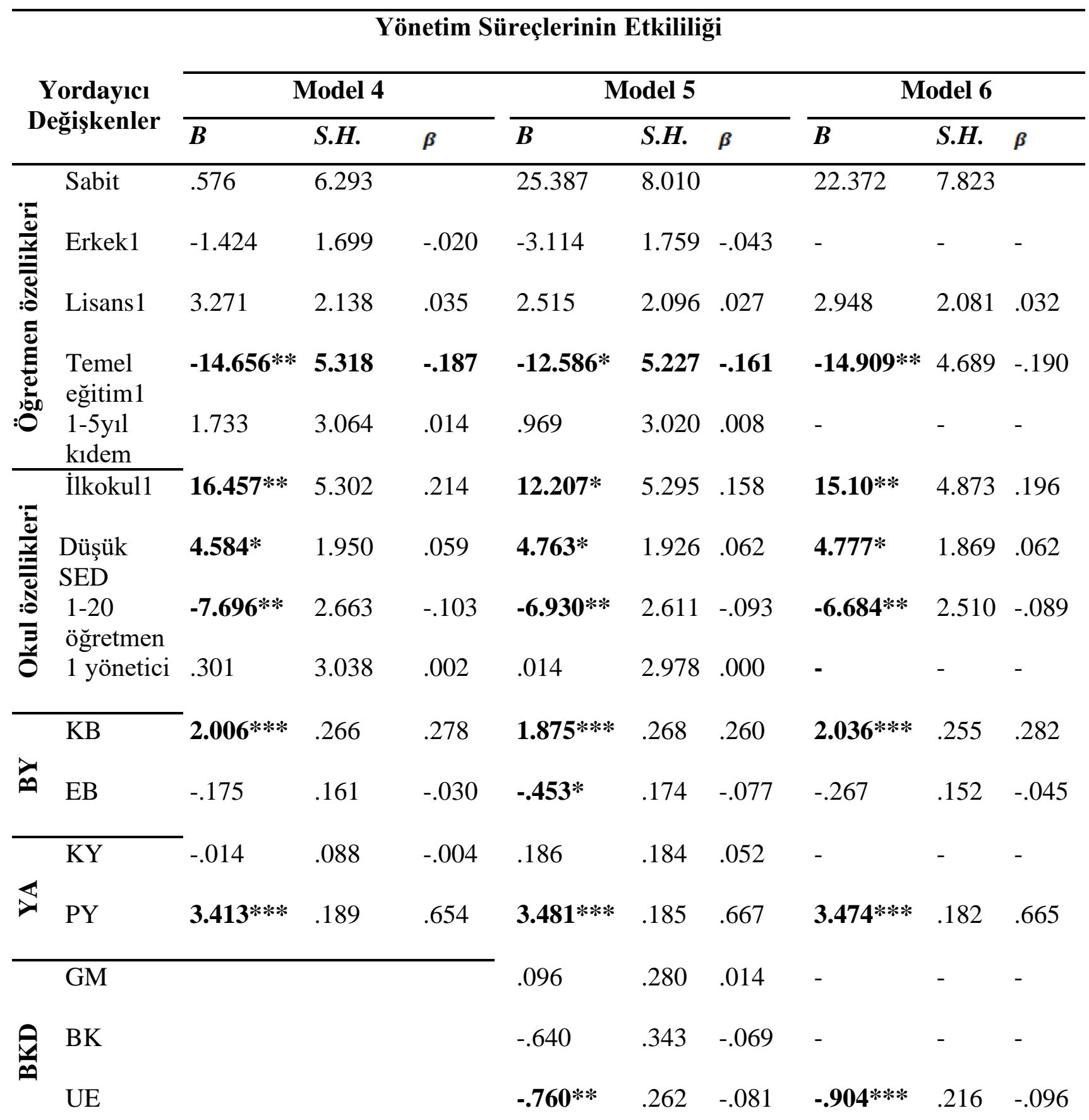




\begin{tabular}{llll}
\hline $\mathbf{R}$ & .893 & .900 & .897 \\
$\mathbf{R}^{\mathbf{2}}$ & $\mathbf{. 7 9 8}$ & $\mathbf{. 8 1 0}$ & $\mathbf{. 8 0 5}$ \\
Düz.R & .792 & .803 & .801 \\
$\Delta \mathbf{R}^{\mathbf{2}}$ & $\mathbf{. 1 6 8}$ & $\mathbf{. 0 1 3}$ & $\mathbf{. 8 0 5}$ \\
\hline
\end{tabular}

$* p<.05 \quad * * p<.01 \quad * * * p<.001$

SED-Sosyoekonomik düzey, KY-Kaotik Yönetim, PY-Pozitivist Yönetim, YA-Yönetim Anlayışı, GM-Güç Mesafesi, BK-Belirsizlikten Kaçınma, K-Kolektivizm, UE-Uzun Erimlilik, E-Erillik, BKD-Bireysel Kültürel Değerler, BY-Bürokratik Yapı, KB-Kolaylaştırıcı Bürokrasi, EB-Engelleyici Bürokrasi, YSE-Yönetim Süreçlerinin Etkililiği

Birinci model incelendiğinde, öğretmen özelliklerinin (cinsiyet=erkek1, eğitim durumu=lisans1, branş=temel eğitim1, kıdem=1-5y1l) yönetim süreçlerinin etkililiğine anlamlı bir katkısının olmadı̆̆ı görüldü $\left[\mathrm{R}^{2}=.019 ; \mathrm{p}=.093>.05\right]$. Ancak modelde eğitim durumunun [eğitim durumu=lisans $1 ; \mathrm{B}=10.136 ; \mathrm{p}<0.05$ ] yönetim süreçlerinin etkililiğine anlamlı katkısının bulunduğu görüldü. Birinci modele göre, öğretmen özelliklerinin yönetim süreçlerinin etkililiği üzerinde anlamlı bir etkisinin olmadığı söylenebilir.

İkinci modelde analize dâhil edilen okul özelliklerinin (okul türü=ilkokul1, sosyoekonomik düzey=düşük, öğretmen sayısı=1-20 öğretmen, yönetici sayısı=1 yönetici) yönetim süreçlerinin etkililiği üzerinde anlamlı katkısının olmadığı görüldü $\left[\mathrm{R}^{2}=.031\right.$; $\Delta \mathrm{R}^{2}=.012 ; \mathrm{p}=.273>.05$ ]. Ancak modelde eğitim durumunun [eğitim durumu=lisans1; $\mathrm{B}=10.849 ; \mathrm{p}=.019<0.05]$ yönetim süreçlerinin etkililiğine anlamlı katkısının bulunduğu görüldü. İkinci modelin etki büyüklüğü $f^{2}=\left(\mathrm{r}_{2}^{2}-\mathrm{r}_{1}^{2}\right) /\left(1-\mathrm{r}_{1}^{2}\right)=[(0.031-0.019) /(1-0.019)]=0.01$ olarak hesaplandı ve etki büyüklüğünün düşük düzeyde olduğu görüldü. İkinci modele göre, okul özelliklerinin yönetim süreçlerinin etkililiği üzerinde anlamlı bir etkisinin olmadığı söylenebilir.

Üçüncü modelde analize dâhil edilen okul yapısına yönelik bileşenlerin (kolaylaştırıcı bürokrasi, engelleyici bürokrasi) yönetim süreçlerinin etkililiği üzerinde anlamlı katkısının bulunduğu görüldü $\left[\mathrm{R}^{2}=.630 ; \Delta \mathrm{R}^{2}=.598 ; \mathrm{p}=.000<0.001\right]$ ve açıklanan varyansı \%63'e çıkardığı görüldü. Ayrıca bu modelde sadece kolaylaştırıcı bürokrasinin $[\mathrm{B}=5.402 ; \mathrm{p}=.000<0.001]$ ve engelleyici bürokrasinin $[\mathrm{B}=-.485 ; \mathrm{p}=.022<0.05]$ yönetim süreçlerinin etkililiğine anlamlı katkısının bulunduğu görüldü. Buna göre, kolaylaştırıcı bürokratik yapıdaki 1 birimlik artış yönetim süreçlerinin etkililiğinde 5,402 birimlik artışa, engelleyici bürokratik yapıdaki 1 birimlik artış yönetim süreçlerinin etkililiğinde 0,485 azalışa neden olduğu görüldü. Bu modelde açıklanan varyansın \%60'nın okul yapısı 
tarafından açıklandığı görüldü $\left[\Delta \mathrm{R}^{2}=0.598 ; \mathrm{p}=.000<0.001\right]$. Üçüncü modelin etki büyüklüğü $f^{2}=\left(\mathrm{r}_{2}^{2}-\mathrm{r}_{1}^{2}\right) /\left(1-\mathrm{r}_{1}^{2}\right)=[(0.630-0.031) /(1-0.031)]=0.62$ olarak hesapland1 ve etki büyüklüğünün yüksek düzeyde olduğu görüldü. Üçüncü modele göre, okullarda kolaylaştırıcı bürokratik yapı arttıkça yönetim süreçlerinin etkililiğinin artacağı söylenebilir.

Dördüncü modelde analize dâhil edilen yönetim anlayışına yönelik bileşenlerin (kaotik yönetim ve pozitivist yönetim) yönetim süreçlerinin etkililiği üzerinde anlamlı katkısının bulunduğu $\left[\mathrm{R}^{2}=.798 ; \Delta \mathrm{R}^{2}=.168 ; \mathrm{p}=.000<0.0001\right]$ ve açıklanan varyans1 \%79.8'e çıkardığı görüldü. Ayrıca bu modelde branşın [branş=Temel eğitim; B=-14.656; $\mathrm{p}=.006<0.01$ ], okul türünün [okul türü=Illkokul1; $\mathrm{B}=16.457 ; \mathrm{p}=.002<0.01$ ], sosyoekonomik düzeyin [sed=düşük; $B=4.584 ; p=.019<0.05$ ], öğretmen sayısının [öğretmen sayısı1=1-20 öğretmen; $B=-7.696 ; p=.004<0.01]$, kolaylaştırıcı bürokrasinin [B=2.006; $p=.000<0.001]$ ve pozitivist yönetim anlayışının $[\mathrm{B}=3.413 ; \mathrm{p}=.000<0.001]$ yönetim süreçlerinin etkililiğine anlamlı katkısının bulunduğu görüldü. Bu modelin varyansın \%16,8‘ini açıkladığı görüldü $\left[\Delta \mathrm{R}^{2}=0.168 ; \mathrm{p}=.000<0.001\right]$. Dördüncü modelin etki büyüklüğü $f^{2}=\left(\mathrm{r}_{2}{ }^{2}-\mathrm{r}_{1}{ }^{2}\right) /\left(1-\mathrm{r}_{1}{ }^{2}\right)=[(0.798-$ 0.630)/(1-0.630)]=0.45 olarak hesaplandı ve etki büyüklüğünün yüksek düzeyde olduğu görüldü. Dördüncü modele göre, okullarda kolaylaştırıcı bürokratik yapının ve pozitivist yönetim anlayışının yönetim süreçleri üzerinde etkili olduğu söylenebilir.

Beşinci modelde analize dâhil edilen bireysel kültürel değerlere yönelik bileşenlerin (güç mesafesi, belirsizlikten kaçınma, uzun erimlilik, erillik) yönetim süreçlerinin etkililiği üzerinde anlamlı katkısının bulunduğu $\left[\mathrm{R}^{2}=.810 ; \Delta \mathrm{R}^{2}=.013 ; \mathrm{p}=.000<0.001\right]$ ve toplam açıklanan varyansı \%81'e çıkardığı görüldü. Ayrıca bu modelde branşın [branş=Temel eğitim1; $\mathrm{B}=-12.586 ; \quad \mathrm{p}=.016<0.05$ ], okul türünün [okul türü=İlkokul; $\mathrm{B}=12.207$; $\mathrm{p}=.022<0.05$ ], sosyoekonomik düzeyin [sed=düşük; $\mathrm{B}=4.763 ; \mathrm{p}=.014<0.05$ ], öğretmen sayısının [öğretmen sayısı=1-20 öğretmen; $B=-6.930 ; \quad p=.008<0.01]$, kolaylaştırıcı bürokrasinin $[\mathrm{B}=1.875 ; \mathrm{p}=.000<0.001]$, engelleyici bürokrasinin $[\mathrm{B}=-.453 ; \mathrm{p}=.010<0.05]$, pozitivist yönetim anlayışının $[\mathrm{B}=3.481 ; \mathrm{p}=.000<0.001]$, ve uzun erimliliğin $[\mathrm{B}=-.760$; $\mathrm{p}=.004<0.01]$ yönetim süreçlerinin etkililiğine anlamlı katkısının bulunduğu görüldü. $\mathrm{Bu}$ modelin varyansın \%1,3'ünü açıkladığı görüldü $\left[\Delta \mathrm{R}^{2}=0.013 ; \mathrm{p}=.000<0.001\right]$. Beşinci modelin etki büyüklüğü $f^{2}=\left(\mathrm{r}_{2}^{2}-\mathrm{r}_{1}^{2}\right) /\left(1-\mathrm{r}_{1}^{2}\right)=[(0.810-0.798) /(1-0.798)]=0.06 \quad$ olarak hesaplandı ve etki büyüklüğünün yüksek düzeyde olduğu görüldü. Beşinci modele göre, okullarda kolaylaştırıcı bürokratik yapının, pozitivist yönetim anlayışının ve uzun erimlilik kültürel değerinin yönetim süreçleri üzerinde etkili olduğu söylenebilir. 
Altınc1 modelde de tüm modellerde yönetim sürecinin etkililiği üzerinde anlamlı etkisi tespit edilen değişkenler (eğitim durumu=lisans, branş=temel eğitim, okul türü=ilkokul, sed=düşük, öğretmen sayısı=1-20öğretmen, kolaylaştırıc1 bürokrasi, engelleyici bürokrasi, pozitivist yönetim, uzun erimlilik) tekrar regresyon analizine dâhil edildi. Bu modeldeki bağımsız değişkenlerin yönetim süreçlerinin etkililiği üzerinde anlamlı katkısının bulunduğu ve toplam açıklanan varyansın $\% 80.5$ olduğu görüldü $\left[\mathrm{R}^{2}=.805\right.$; $\mathrm{p}=.000<0.001]$. Ayrıca bu modelde branşın $\quad[$ branş=Temel eğitim; $\mathrm{B}=-14.909$; $\mathrm{p}=.002<0.001$ ], okul türünün (okul türü1=Illkokul1; $\mathrm{B}=15.100 ; \mathrm{p}=.002<0.01$ ), öğretmen sayısının [öğretmen sayısı1 $=1-20$ öğretmen; $B=-6.684 ; \mathrm{p}=.008<0.01$ ], sosyoekonomik düzeyin [sed1=düşük; $\mathrm{B}=4.777 ; \mathrm{p}=.011<0.05]$, pozitivist yönetim anlayışının $[\mathrm{B}=3.474$; $\mathrm{p}=.000<0.001]$, kolaylaştıııcı bürokrasinin $[\mathrm{B}=2.036 ; \mathrm{p}=.000<0.001]$ ve uzun erimliliğin $[\mathrm{B}=-.904 ; \mathrm{p}=.000<0.001]$ yönetim süreçlerinin etkililiğine anlamlı katkısının bulunduğu görüldü. Altınc1 modelin etki büyüklüğü $f^{2}=\left(\mathrm{r}_{2}^{2}-\mathrm{r}_{1}^{2}\right) /\left(1-\mathrm{r}_{1}^{2}\right)=[(0.808-0.814) /(1-0.814)]=0.03$ olarak hesaplandı ve etki büyüklüğünün yüksek düzeyde olduğu görüldü. Altıncı modele göre, okullarda kolaylaştırıcı bürokratik yapının, pozitivist yönetim anlayışının ve uzun erimlilik kültürel değerinin yönetim süreçleri üzerinde etkili olduğu söylenebilir.

\section{Tartışma, Sonuç ve Öneriler}

$\mathrm{Bu}$ araştırmada, eğitim kurumlarında yönetim anlayışının, bürokratik yapının ve kültürel değerlerin, yönetim süreçleri üzerindeki etkisi incelenmiştir.

Araştırma sonucunda katılımcı öğretmenlerin görev yaptıkları eğitim kurumlarında çoğunlukla yüksek düzeyde kolaylaştırıcı bürokratik yapı algısına, nadiren de engelleyici bürokratik yapı algısına sahip oldukları tespit edildi. Araştırma bulgularına benzer şekilde Özer (2010) okullarda kolaylaştııııı bürokratik yapının hâkim olduğunu, bazen de engelleyici bürokratik yapının algılandığını belirtmektedir. Alanda kolaylaştırıcı bürokratik yapının yüksek düzeyde algılandığı bazı çalışmalar da bu araştırmanın bulgularıyla paralellik göstermektedir (Alev, 2019; Buluç, 2009; Kotnis, 2004; Messick, 2012; Yılmaz ve Beycioğlu, 2017). Yapılan çalışmalarda kolaylaştııııı bürokratik yapıya sahip okullarda, öğretmenleri destekleyen, demokratik ve adil ortamların olduğu vurgulanmaktadır (Messick, 2012; Yılmaz ve Beycioğlu, 2017). Aynı zamanda alanda engelleyici bürokratik yapının daha etkin olarak algılandığı çalışmalara da rastlanmaktadır (Cerit, 2012; Karaman ve Akıl, 2004). Bazı çalışmalarda ilköğretim okullarının daha fazla engelleyici bürokratik yapıya sahip oldukları belirtilmektedir (Cerit, 2012). Engelleyici bürokratik yapıya sahip okullarda, öğretmenleri zorlayıcı katı kural ve düzenlemelerin olduğu, yakından denetleme ve 
cezalandırma mekanizmalarının daha fazla etkin kullanıldığı vurgulanmaktadır (Hoy ve Sweetland, 2001). Araştırmada beklendiği gibi, okullarda kolaylaştırıcı bürokrasinin yönetim süreçlerinin etkililiğinin arttığı; engelleyici bürokrasinin ise, yönetim süreçlerinin etkililiğini azalttığı tespit edildi. Okullara yönelik yapılan araştırmalar, okulların yapısal özelliklerinin birbirinden farklılaştığını göstermekle birlikte (Hoy, 2003; Hoy ve Miskel, 2010; Hoy ve Sweetland, 2000,2001; Sinden vd.,2004), okullarda engelleyici bir yapının aksine kolaylaştırıcı bir okul yapısının oluşturulmasını gerektirmektedir (Hoy ve Sweetland, 2001). Weick ve Sutcliffe (2001), okulların kolaylaştırıcı bürokratik yapısının, meslektaş iş birliğini olumlu etkilediğini ve akademik başarıya olumlu katkı sağladığını belirtmektedir. Wu vd.(2013) da benzer şekilde kolaylaştırıcı okul yapısında yönetici ve öğretmenlerin iş birliği içinde hareket ettiklerine, sorunların çözümüne yönelik birlikte karar aldıklarına ve yöneticilerin, öğretmenlerin daha etkili görev yapabilecekleri yapıları desteklediklerine dikkat çekmektedir. Watts (2009) kolaylaştırıcı okul yapısı arttıkça, çalışanların örgütsel duyarlılığının arttığını belirtmektedir. Özer (2010) de kolaylaştırıcı bürokratik yapının, örgüt normları ve örgütsel diriklik üzerinde olumlu etkisinin olduğunu vurgulamaktadır. McGuigan ve Hoy (2006) ise, okullarda kolaylaştırıcı bürokratik yapı algısının artmasının çalışanların akademik iyimserlik düzeylerini doğrudan etkilediğini, çalışanların akademik iyimserlik düzeylerinin artmasının da öğrencilerin akademik başarısını olumlu yönde arttıracağını belirtmektedir. Antonelli (2005) de okulların kolaylaştırıcı bürokratik yapısının, olumlu okul iklimi, kolektif öz-yeterlik ve okul etkililiği üzerindeki etkisine dikkat çekmektedir. Diğer taraftan Dzubay (2001) okullarda çalışanlar belirli kurallara uymaya zorlandığında, engelleyici bürokrasinin, onların motivasyonunu azalttığı ve olumsuz tepkiler gösterdiklerini belirtmektedir. Alandaki çalışmalardan ve bu çalışmanın bulgularından hareketle, engelleyici bürokratik yapının aksine kolaylaştırıcı bürokratik yapı, çalışanların hem örgüte hem işlerine karşı duyarlılık ve bağlılıklarını artırmakta, iş birliğini, örgüt iklimini ve örgütsel etkililiği olumlu olarak etkilemekte, dolayısıyla örgütteki yönetsel süreçlerin etkililiğine olumlu katkı sağladığı görülmektedir. Bu açıklamalar ışığında ve bulgular kapsamında araştırmada $\mathrm{H}_{1}$ hipotezi kabul edildi.

Araştırma sonuçlarına göre, öğretmenlerin, okullarda çoğunlukla yüksek düzeyde pozitivist yönetim anlayışı ve nadiren de kaotik yönetim anlayışı algısına sahip olduğu görüldü. Aynı zamanda, araştırmada hem pozitivist yönetim anlayışının hem de kaotik yönetim anlayışının yönetim süreçleriyle pozitif ilişkiye sahip olduğu; ancak pozitivist yönetim anlayışının, kaotik yönetim anlayışına göre yönetim süreçlerinin etkililiğine daha 
yüksek katkı sağladığı tespit edildi. Benzer şekilde yönetim anlayışının örgütsel ve davranışsal çıktılar üzerinde etkili olduğunu gösteren çalışmalar, yönetim anlayışının yönetim süreçlerine olan etkisini destekler niteliktedir (Ayral ve Tanrı̈ğgen, 2020; Usta, 2013). Ayral ve Tanrı̈ğen (2020) çalışanlara yönelik iyimser bakış açısının hâkim olduğu eğitim örgütlerinde, yönetsel faaliyetlerin daha şeffaf bir şekilde yürütüldüğünü vurgulamaktadır. Usta (2013) ise örgütlerde hem pozitivist hem de kaotik yönetim anlayışının, çalışanların örgütsel bağlılığının artırdığını belirtmektedir (Usta, 2013). Styhre (2001) de kaotik yönetim anlayışının olduğu örgütlerde sürekli değişimin, gelişimin ve dönüşüme açık olan kendi kendini örgütleyen örgüt modellerin varlığına dikkat çekmektedir. Tetenbaum(1998) ise bilgi ve iletişimin hızla yaygınlaştığ 1 günümüzde, yenilik, yaratıcılık, takım çalışması, proje yönetimi, farklılıklara saygı ve korunması gereken değerler kavramlarının öne çıktığını belirtirken, ani gelişim ve değişimlere adaptasyon sağlayan, kaotik yapıya sahip örgüt kurmanın ve kaos kültürünü inşa etmenin bir zorunluluk olduğunu belirtmektedir. Diğer taraftan Tüz (2004) ise pozitivist yönetim anlayışının hâkim olduğu örgütlerde hiyerarşi ve kontrolün örgütsel faaliyetlerin gerçekleştirilmesindeki önemini vurgularken; Açıkalın (1995) da pozitivist yönetim anlayışına sahip örgütlerde yöneticinin başarısını otoritesine borçlu olduğunu ve mevcut statükoyu koruma amacına hizmet ettiğini belirtmektedir. Demirtaş (2006) da her iki yönetim anlayışının da belirli ölçülerde birbirini içinde barındırdığını belirtirken, günümüzde gelişmişlik, büyüklük ve karmaşıklık özelliklerine sahip olan çağdaş örgütlerin yöneticilerinin de bu karmaşayı ve kaosu yönetme becerisine sahip olmaları gerektiğini vurgulamaktadır. Çalışmalardan hareketle ve araştırma sonuçları da dikkate alındığında örgütlerin yapısı ve türüne göre hem kaotik hem de pozitivist yönetim anlayışının her ikisinin de örgütlerde mevcudiyetinden söz etmek yanlış olmayacaktır. Araştırma sonucunda pozitivist yönetim anlayışının yönetim süreçleri üzerinde daha etkili olması, eğitim örgütlerinin Abbott'un (1965) da belirttiği gibi yüksek düzeyde gelişmiş bürokrasiye sahip olmalarından kaynaklandığı söylenebilir. Bununla birlikte, okullarda düzenli ve tutarlı kurallar, önceden belirlenmiş plan ve program, istikrarlı bir hiyerarşik yapının yanında; gelişim ve dönüşüme açık, vizyon sahibi, kendi kendini örgütleyen, esnek, işbirlikçi, yeniliği ve yaratıcılığı destekleyen bir anlayışın da olduğunu göstermektedir. $\mathrm{Bu}$ açıklamalar ışığında ve bulgular kapsamında araştırmada $\mathrm{H}_{2}$ hipotezi kabul edildi.

Araştırmanın bir diğer sonucu olarak, katılımcı öğretmenlerin okullarda kültürel değerlerden çok yüksek düzeyde uzun erimlilik, yüksek düzeyde belirsizlikten kaçınma ve 
kolektivizm, orta düzeyde erillik, düşük düzeyde güç mesafesi algısına sahip oldukları tespit edildi. Hofstede, Hofstede ve Minkov (2010) uzun erimli örgütlerin gelecek yönelimli olduklarını, planlamaya önem verdiklerini, pragmatik davrandıklarını, adanmışlık, çalışkanlık ve tasarruf gibi kültürel değerleri önemsediklerini belirtmektedir. Javidan ve House (2001) belirsizlikten kaçınmanın yüksek olduğu örgütlerin, resmi kurallara dayalı düzenli ve tutarlı bir yapıyı benimsediklerini belirtirken; Yukl (2013) da bu örgütlerde belirsizliğe karşı korku, kaygı ve stresin yüksek olduğunu, çalışanların esnek, yenilikçi ve risk alan yöneticiler yerine; daha güvenli, tutarlı ve düzenli bir ortam arzuladıklarını belirtmektedir. Offerman ve Hellmann (1997) belirsizlikten kaçınmanın yüksek olduğu örgütlerde, yetki devrinin daha az olduğuna, aşırı planlamanın, resmi kuralların ve prosedürlerin uygulanmasına ve değerlendirilmesine daha fazla başvurulduğuna vurgu yapmaktadır. Benzer şekilde mevcut araştırmada hem pozitivist yönetim anlayışının hem de belirsizlikten kaçınmanın daha yüksek algılanması birbirini desteklemektedir. Beklenilen bir sonuç olarak bireyselliğin, kişisel hak ve sorumlulukların ön planda tutulduğu günümüzün aksine, Türk toplumunun genel karakteristik özelliklerinin bir göstergesi olarak mevcut çalışmada kolektivist değerlerin daha yüksek olduğu görüldü. Jackson vd.(2006) toplulukçu kültürel değerlerin baskın olduğu örgütlerde çalışanların işe ve gruba bağlılık düzeylerinin yüksek olduğunu, daha fazla örgütsel vatandaşlık davranışı sergilediklerini ve performanslarını artırmaya yönelik çaba gösterdiklerini vurgulamaktadır. Ayrıca toplulukçu kültürlerde örgütsel amaçlara bağlılığın yöneticilerin işini kolaylaştırdığı (Jung ve Avolio, 1999; Triandis vd.,1994), grup ya da örgüt başarısına yönelik motivasyon kaynaklarının daha etkin kullanıldığı (Kirkman ve Shapiro, 2001) bu durumun ortak değerlere dayalı (iş birliği, etik, sosyal sorumluluk vb.) güçlü bir örgüt kültürünün oluşturulmasını ve sürdürülmesini de kolaylaştırdığı belirtilmektedir (Yukl, 2013). Bu araştırmada, okullarda orta düzeyde eril değerlere yönelik bir algının olduğu tespit edilmesi, bu durumun hala cinsiyet ayrımına dayalı bir anlayışın varlığını da göstermektedir. Hofstede (1980a) eril kültürlerin iddialı, hırslı, rekabetçi, mal varlığı ve paraya önem veren, bireysel ve maddi başarı odaklı özellikler gösterdiğini belirtirken; Sargut (2001) da saldırganlık, yükselme arzusu, yarışmacı, hâkim ve baskıcı özelliklerine vurgu yapmaktadır. Diğer taraftan Hofstede (1980a, 2001) dişil kültürlerin ise daha mütevazı ve hassas olup, güçlü sosyal bağlar, yaşam kalitesi ve diğerlerinin zenginliğine değer verdiklerini; Sargut (2001) da daha şefkatli, merhametli, nazik ve sadık olduklarını belirtmektedir. Yeloğlu (2011) da Türk kültürünün toplumsal anlamda değil de bireysel veya coğrafi anlamda eril özellikler gösterdiğini; ancak geleneklerine bağlılık, saygı ve merhamet konularında toplum olarak en 

azından Batı ülkelere göre daha dişil özellikler gösterdiğini belirtmektedir. Bu araştırmada, öğretmenlerin düşük düzeyde güç mesafesi algısına sahip olduğu görüldü. Hofstede (1980a) güç mesafesi düşük olan kültürlerde, bireylerin bağımsızlık, eşitlik ve dayanışma gibi kavramlara değer verdiklerini belirtmektedir. Diğer taraftan Dickson vd.(2003) güç mesafesi yüksek olan kültürlerde, liderlerin daha çok yetkiye sahip olduğu ve bireylerin kuralları sorgulamadan itaat etme eğilimi gösterdiğini; Adsit vd.(1997) ise bireylerin, fikirlerini açıkça söylemekten çekindiklerini; Smith vd.(2002) de resmi prosedürlerin yoğun bir şekilde işlediğini, çalışanların karar alma süreçlerine daha az dahil edildiğini vurgulamaktadır. Ayrıca bu araştırma, yönetim süreçlerinin etkililiği ile kültürel değerlerin belirsizlikten kaçınma, kolektivizm, güç mesafesi ve uzun erimlilik boyutları arasında olumlu ve düşük düzeyde anlamlı korelasyon olduğu gösterdi. Bu araştırmada öğretmenlerin bireysel kültürel değerlere yönelik algısı ile yönetim süreçlerinin etkililiği arasında düşük düzeyde ilişkinin olması, aileden ve toplumdan gelen kültürel değerlerin yönetim süreçlerine yönelik algılarını çok az etkilediğini göstermektedir. Bu açıklamalar ışığında ve bulgular kapsamında araştırmada $\mathrm{H}_{3}$ hipotezi kabul edildi.

Araştırma sonucunda, katılımcı öğretmenlerin okullardaki yönetim süreçlerini yüksek düzeyde etkili olarak algıladı̆̆ı tespit edildi. Yönetim süreçlerine etki eden değişkenlerin belirlenmesine yönelik yapılan çoklu hiyerarşik regresyon analizi sonucunda, okullarda kolaylaştırıcı bürokratik yapının, pozitivist yönetim anlayışının ve uzun erimlilik kültürel değerinin yönetim süreçleri üzerinde yüksek düzeyde etkiye sahip olduğu; bu değişkenlerin toplam varyansın \%81'ini açıkladığı görüldü. Ayrıca öğretmenlere yönelik değişkenlerden branşın, okula yönelik değişkenlerden okul türü, öğretmen sayısı ve sosyoekonomik düzeyin yönetim süreçleri üzerinde anlamlı etkisinin olduğu tespit edildi. Yıldırım ve Açıl (2020) okul yöneticilerinin yönetim süreçlerinin etkililiğinin artırmak için karar verme, iletişim ve değerlendirme süreçlerine öğretmenlerin dahil edilmesinin okullarda örgütsel adalet algısını artıracağını vurgulamaktadır. Kim ve Kim (2005) ise okul yöneticilerinin kendi kurumsal yapısındaki işleyişi kolaylaştırma, sorun çözme ve bir sosyal değişim ajanı olma bakımından okulda tüm temel karar verme mekanizmalarının merkezi olduğunu belirtmektedir. Dolayısıyla eğitim kurumlarında öğretmenlerin okullardaki yönetim süreçlerine ilişkin yüksek algıya sahip olmaları, okul yöneticilerinin etkili ve başarılı bir yönetim sergilemelerinden kaynaklandığı söylenebilir. Bu bulgular ve açıklamalar 1şı̆̆ında bu araştırma kapsamında $\mathrm{H}_{4}$ hipotezi kabul edildi. 
$\mathrm{Bu}$ araştırma, okullarda pozitivist yönetim anlayışının, bürokratik işleyişin kolaylaştırıcı özelliğe sahip olmasının ve geleceğe yönelik uzun vadeli güvenilir planlama yapabilmenin yönetim süreçlerinin üzerinde etkili olduğunu ortaya koymuştur. $\mathrm{Bu}$ araştırmadaki bulgulardan hareketle, eğitim örgütlerinde hem yöneticilerin hem de okulların etkili ve başarılı olmasının yönetim süreçlerinin etkililiğine bağlı olduğunu göstermektedir. Bu noktada okullarda, demokratik bir ortamın tesis edilmesi, branşlar arasındaki ayrıma yönelik algının iyi yönetilmesi, okul türleri ve okulların sosyoekonomik düzeyleri arasındaki farklılıkların asgari düzeye indirebilecek politika ve uygulamaların geliştirilmesi, öğretmen ve öğrenci sayısıyla orantılı olarak yönetici sayısının dengeli dağıtılması yönetsel süreçlerin daha etkili yürütülmesini olumlu katkı sağlayacaktır. Ayrıca ani ve sürekli değişimlerin gerekçeleri açıklanmasının, kaos ve kriz ortamının çalışanlarda yaratacağı kaygı ve stresin engellenmesinin, değişimlerin sonuçlarının takibinin yapılmasının, bireysel ve örgütsel bürokratik işlerin kolaylaştırıcı olmasının, okullarda istikrar ve güven ortamının tesis edilmesinin adanmışılı ve bağlılık gibi davranışsal çıktıların yanında hem yönetim süreçlerin etkililiği hem de örgütsel ve sistemsel etkililik üzerinde önemli katkılar sağlayacağı düşünülmektedir. Ayrıca bu araştırmada, yönetim anlayışının, okulun bürokratik yapısının ve kültürel değerlerin yönetim süreçlerinin etkililiğinin büyük bir çoğunluğunu yordamasından hareketle, açıklanamayan varyansın farklı örgütsel davranış ve çıktılarla (örgüt iklimi ve kültürü, liderlik, örgütsel etkililik, motivasyon, iş performansı, iş tatmini vb.) araştırılması ve farklı araştırma yaklaşımlarıyla (nitel, karma vb.) incelenmesi alana katkı sağlayabilir.

Etik Kurul İzin Bilgisi: Bu araştırma, Akdeniz Üniversitesi Sosyal ve Beşeri Bilimler Bilimsel Araştırma ve Yayın Etiği Kurulunun 17/09/2021 tarihli 307 sayılı kararı ile alınan izinle yürütülmüşı̈r.

Yazar Çıkar Çatışması Bilgisi: Yazarlar çıkar çatışması olmadığını beyan etmektedir.

Yazar Katkısı: Yazarlar çalışmaya eşit oranda katkı sağlamıştır. 


\section{Kaynakça}

Abbott, M. (1965).Hierarchical impediments to innovation in educational organizations. In M.Abbott and J. Lovell (Eds.), Change perspectives in educational administration (pp.40-53). Auburn, AL: Auburn University.

Abbott, M., \& Caracheo, F. (1988). Power, authority, and bureaucracy. In N.J. Boyan (Ed.), Handbook of research on educational administration (pp.235-257). New York: Longman.

Açıkalın, A. (1995). Toplumsal, kuramsal ve teknik yönleriyle okul yöneticiliği. Ankara: Personel Geliştirme Merkezi.

Aç11, Y. (2020). Okul yönetiminde yönetim süreçlerinin etkililiği ile örgütsel adalet arasındaki ilişsk. Yayınlanmamış yüksek lisans tezi, Necmettin Erbakan Üniversitesi, Konya.

Adsit, D.J., London, M., \& Jones, D. (1997). Cross-cultural differences in upward rating in a multi-cultural company. International Journal of Human Resource Management, 8, $385-401$.

Aiken, L.S., \& West, S.G. (1991). Multiple regression:Testing and interpreting interactions. Newbury Park CA: Sage.

Akyol, B. (2013). Üniversitelerdeki örgütsel adalet olgusunun öğretim elemanları algllarına göre yönetim süreçleri açısından değerlendirilmesi. Yayımlanmamış doktora tezi, On sekiz Mart Üniversitesi, Çanakkale.

Albayrak, A.S. (2005). Çoklu doğrusal bağlantı halinde en küçük kareler tekniğinin alternatifi yanlı tahmin teknikleri ve bir uygulama. ZKÜ Sosyal Bilimler Dergisi, l(1), 105-126.

Alev, S. (2019). Kolaylaştırıcı okul yapısı ve örgütsel vatandaşlık davranışları arasındaki ilişkinin incelenmesi. OPUS-Uluslararası Toplum Araştırmaları Dergisi, 10(17), 420-443.

Antonelli, L.A. (2005). Organizational and SES predictors of student achievement and school effectiveness. Unpublished doctoral dissertation, St. John's UniversityJamaica, New York.

Aslanargun, E. (2007). Modern eğitim yönetimi anlayışına yönelik eleştiriler ve postmodern eğitim yönetimi. Kuram ve Uygulamada Eğitim Yönetimi, 50(50), 195-212.

Aydın, M. (2018). Eğitim yönetimi. Ankara: Gazi Kitabevi. 
Aydın, E. (2019). Temel eğitim kurumlarl yöneticilerinin görüşlerine göre yönetim süreçlerinin değerlendirilmesi. Yayınlanmamış yüksek lisans tezi, Necmettin Erbakan Üniversitesi, Konya.

Aydoğan, İ.Y. (1998). Özel okullarda yönetim süreçlerinin işleyişi (Kayseri ili örneği). Yayınlanmamış yüksek lisans tezi, Ankara Üniversitesi, Ankara.

Ayral, T.ve Tanrı̈ğgen, A. (2020). Okul müdürlerinin yönetim felsefeleri ile okulların şeffaflık düzeyleri arasındaki ilişki. Journal of International Social Research, 13(75), 585-594.

Balc1, A. (2018). Sosyal bilimlerde araştırma yöntem, teknik ve ilkeler (13.Bask1). Ankara: Pegem Akademi.

Başaran, İ.E. (2008). Türk eğitim sistemi ve okul yönetimi. Ankara: Ekinoks Yayınevi.

Bateman, T.S., \& Snell, S.A. (2013). Management. New York, NY: McGraw-Hill.

Bulaç, A. (1990). Din ve modernizm. İstanbul: Endülüs Yayınları.

Buluç, B. (2009).İlköğretim okullarında bürokratik okul yapısı ile okul müdürlerinin liderlik stilleri arasındaki ilişki. Ĕgitim ve Bilim, 34(152), 71-86.

Bursalığlu, Z. (2015). Okul yönetiminde yeni yapı ve davranış. Ankara: Pegem Yayıncılık.

Bush, T. (1995). Theories of Educational Management. London: PCP.

Büte, M.ve Balcı, A.F. (2010). Bağımsız anaokulu yöneticilerinin bakış açısından okul yönetimi süreçlerinin işleyişi ve sorunlar. Kuram ve Uygulamada Eğitim Yönetimi Dergisi, 16(4), 485-511.

Büyüköztürk, Ş. (2016). Sosyal bilimler için veri analizi el kitabı: Istatistik, araştırma deseni, spss uygulamalarl ve yorum (22.bask1). Ankara: Pegem Akademi.

Büyüköztürk, Ş., Çakmak, E.K., Akgün, Ö.E., Karadeniz, Ş., Demirel, F. (2008). Bilimsel araştırma yöntemleri. Ankara: Pegem Akademi.

Cerit, Y. (2012). Okulun bürokratik yapısı ile sınıf öğretmenlerinin profesyonel davranışları arasındaki ilişki. Kuram ve Uygulamada Eğitim Yönetimi, 18(4), 497-521.

Cohen, J., Cohen, P.,West, S.G., \& Aiken, L.S.(2003). Applied multiple regression/ correlation analysis for the behavioral sciences. Mahwah, NJ: Erlbaum.

Corwin, R.G., \& Borman, K.M. (1980). School as a workplace: Structural constraints on administration. In N.J. Boyan (Ed.), Handbook of research on educational administration (pp.209-237). New York: Longmen.

Çokluk, Ö., Şekercioğlu, G.ve Büyüköztürk, Ş. (2018). Sosyal bilimler için çok değişkenli istatistik SPSS ve LISREL uygulamalart. Ankara: Pegem Akademi. 
Çoruk, A. (2012). Yönetim süreçleri açısından yöneticilerin duygu yönetimi davranışları. Yayınlanmamış doktora tezi, On sekiz Mart Üniversitesi, Çanakkale.

Dess, G.G., \& Picken, J.C. (2000). Changing roles: Leadership in the 21 st century. Organizational Dynamics, 28(3), 18-33.

Demirtaş, H. (2006). Yönetim kuram ve yaklaşımları eğitiminin ilköğretim okulu öğretmenlerinin sınıf yönetimi paradigmalarına etkileri. Eğitimde Politika Analizleri ve Stratejik Araştırmalar Dergisi (INASED), 1(1), 49-70.

Dickson, M.W., Den Hartog, D.N., \& Michelson, J.K. (2003). Research on leadership in a cross-cultural context: Making progress and raising new questions. Leadership Quarterly, 14, 729-768.

Dzubay, D. (2001). Understanding motivation\&supporting teacher renewal. Portland,OR: Northwest Regional Educational Laboratory.

Erdoğan, İ. (2003). Okul yönetimi ve öğretim liderliği. İstanbul: Sistem yayıncılık.

Fayol, H. (1916). Industrial and general administration. Paris: Dunod.

Field, A. (2009). Discovering statistics using SPSS (Third Ed.). London: Sage Publication.

Fraenkel, J.R., \& Wallen, N.E. (2006). How to design and evaluate research in education(6th Ed.). New York: McGraw-Hill.

Firestone, W.A., \& Herriott, R.E. (1981). Images of organization and the promotion of change. Research in the Sociology of Education and Socialization, 2, 221-260.

Gelfand, M.J., Bhawuk, D.P.S., Nishi, L.H., \& Bechtold, D.J. (2004). In R.J. House, P.J. Hanges, M. Javidan, P.W. Dorfman, \& V. Gupta (Ed.), Leadership, culture, and organizations: The GLOBE study of 62 societies, C.1.Thousand Oaks, CA: Sage, p.437-512.

Gregg, R.T. (1957). The administrative process. In administrative behavior in education, eds, R.F. Campbell and R.R. Gregg. New York: Harper \& Row, Publishers.

Griffin, R.W., \& Moorhead, G. (2014). Organizational behavior: Managing people and organizations. Mason, $\mathrm{OH}$ : South Western Cengage Learning.

Gül, İ. (2017). Yönetim süreçlerinin etkililiği ölçeği: Geçerlik ve güvenirlik çalışması. Journal of Human Sciences, 14(2), 1370-1387.

Hofstede, G. (1980a). Motivation, leadership, and organization: Do American theories apply abroad?. Organizational Dynamics, 9(1), 42-63.

Hofstede, G. (1980b). Culture's consequences: International differences in workrelated values. Beverly Hills, CA: Sage. 
Hofstede, G. (1981). Culture and organizations. International Studies of Management \& Organization, 10(4), 15-41.

Hofstede, G. (1983). National cultures in four dimensions. A research-based theory of cultural differences among nations. International Studies of Management \& Organization, 13(12), 46-74.

Hofstede, G. (2001). Culture's consequences: Comparing values, behaviors, institutions and organizations across nations,(2.Edition). London (UK): Sage Publications.

Hofstede, G., \& Bond, M.H. (1988). The Confucius connection: From cultural roots to economic growth. Organizational Dynamics, 16(4), 5-21.

Hoftede, G., Hofstede, G.J., \& Minkov, M. (2010). Cultures and organizations: Software of the mind: Intercultural cooperation and its importance for survival. New York: McGraw-Hill.

Hoy, W.K. (2003). An analysis of enabling and mindful school structures: Some theoretical, research, and practical considerations. Journal of Educational Administration, 41, 87-108.

Hoy, W.K., \& Miskel, C.G. (2010). Educational administration: Theory, research and practice. New York: McGraw-Hill.

Hoy, W., \& Sweetland, S. (2000). Bureaucracies that work: Enabling, not coercive. Journal of School Leadership, 10(6), 525-541.

Hoy, W.K., \& Sweetland, S.R. (2001). Designing better schools: The meaning and nature of enabling school structure. Educational Administration Quarterly, 37, 296-321.

Jackson, C.L., Colquitt, J.A., Wesson, M.J., \& Zapata-Phelan, C.P. (2006). Psychological collectivism: A measurement validation and linkage to group member performance. Journal of Applied Psychology, 91(4), 884-899.

Jung, D.I., \& Avolio, B.J. (1999). Effects of leadership style and followers' cultural orientation on performance in group and individual task conditions. Academy of Management Journal, 42, 208-218.

Karaman, M.K.ve Ak1l, Ü.G. (2004). Bürokrasi ve ilköğretimde örgütsel sağlık. Afyon Kocatepe Üniversitesi Sosyal Bilimler Dergisi, 6(2), 15-38.

Karasar, N. (2017). Bilimsel araştırma yöntemi: Kavramlar, ilkeler, teknikler (32.basım). Ankara: Nobel Yayıncılık.

Kim, P.E., \& Kim, S. (2005). Profiles of schools administrators in South Korea: A comparative perspective. Educational Management Administration \& Leadership, 33(3), 286-310. 
Kirkman, B.L., \& Shapiro, D.L. (2001). The impact of cultural values on job satisfaction and organizational commitment in self managing work teams. Academy of Management Journal, Mississippi State, 44(3), 557-569.

Kluckhohn, F.R., \& Strodtbeck, F.L. (1961). Variations in value orientations. New York: Harper Collins

Kotnis, B. (2004). Enabling bureaucracies in education: A case study of formalization in an urban district and schools. Unpublished doctoral dissertation, The State University of New York at Buffalo- Buffalo, NY.

McGuigan, L., \& Hoy, W.K. (2006). Principal leadership: Creating a culture of academic optimism to improve achievement for all students. Leadership and Policy in Schools, 5(3), 203-229.

Mertler, C.A., \& Vannatta, R.A. (2005). Advanced and multivariate statistical methods:Practical application and interpartion (Third Ed.). Glendale, CA: Pyrczak Publishing.

Messick, P.P. (2012). Examining relationships among enabling school structures, academic optimism and organizational citizenship behaviors. Unpublished doctoral dissertation, Auburn University, Auburn, Alabama, USA.

Miles, M.B. (1965). Education and innovation: The organization in context. In M. Abbott and J. Lovell (Eds.), Changing perspectives in educational administration (pp.5472). Auburn, AL: Auburn University.

Mintzberg, H.(2014). Örgütler ve yapıları (Çev. Ed. A. Aypay). Ankara: Nobel Akademi Yayınc1lık.

Offermann, L.R., \& Hellmann, P.S. (1997).Culture's consequences for leadership behavior:National values in action. Journal of Cross Cultural Psychology, 28(3), $342-351$.

Özer, N. (2010). İlköğretim okullarının örgütsel diriklik, bürokratiklik ve örgüt normları açısından analizi. Yayınlanmamış doktora tezi, İnönü Üniversitesi, Malatya.

Özer, N.ve Dönmez, B. (2013). Kolaylaştırıcı okul yapısı ölçeğinin Türkçe formunun psikometrik özelliklerinin yeniden değerlendirilmesi. Pegem Ĕ̆itim ve Öğretim Dergisi, 3(4), 57-68.

Palmberg, K. (2009). Complex Adaptive Systems As Metaphors For Organizational Management. The Learning Organization, 16(6), 483-498.

Robbins, S.P. (1998). Organizational behavior:Concepts, controversies, applications. Upper Saddle, NJ: Allyn and Bacon. 
Robbins, S.P., Decenzo, D.A., \& Coulter, M. (2013). Fundamentals of management: Essential concepts and applications. New Jersey: Prentice Hall.

Roscoe, J.T. (1975). Fundamental research statistics for the behavioral sciences (Second Edition). New York: Holt Rinehart \& Winston.

Sargut, A.S. (2001). Kültürlerarası farklılaşma ve yönetim. Ankara: İmge.

Saylık, A. (2019). Hofstede'nin kültür boyutları ölçeğinin Türkçeye uyarlanması: Geçerlik ve güvenirlik çalışması. Uluslararası Türkçe Edebiyat Kültür Eğitim Dergisi, 8(3), 1860-1881.

Scarborough, J. (1998). The origins of cultural differences and their impact on management. Westport, CT: Quorum.

Smith, P.B., Peterson, M.F., Schwartz, S.H., Ahmad, A.H., \& Associates (2002). Cultural values, sources of guidance, and their relevance to managerial behavior: A 47-nation study. Journal of Cross-Cultural Psychology, 33(2), 188-208.

Sinden, J., Hoy, W.K., \& Sweetland, S.R. (2004). Enabling school structures: Principal leadership and organizational commitment of teachers. Journal of School Leadership, 14(2), 195-210.

Steers, R.M., Sanchez-Runde, C.J., \& Nardon, L.(2010). Management across cultures: Challenges and strategies. Cambridge University Press.

Styhre, A. (2001). The nomadic organization: The postmodern organization of becoming. Tamara: Journal of Critical Postmodern Organization Science, 1(4), 1-12.

Summak, M.S.ve Yazgan, H. (2007). İlköğretim okulu müdürlerinin yönetim süreçlerini kullanma etkinlikleri ile bazı duygusal, sosyal ve ruhsal yeterlilikleri arasındaki ilişkinin incelenmesi (Kilis İli Örneği). Türk Eğitim Bilimleri Dergisi, 5(2), 261-290.

Tabachnick, B.G., \& Fidell, L.S. (2013). Using multivariate statistics (Sixth ed.). United States: Pearson Education

Tetenbaum, T.J. (1998). Shifting paradigms: From Newton to chaos. Organizational Dynamics, Spring, 21-32.

Triandis, H.C. (1995). Individualism and collectivism. Boulder, CO: Westview Press.

Triandis, H.C., Kurowski, L.L., \& Gelfand, M.J. (1994). Workplace diversity. In H.C. Triandis, M.D. Dunnette, \& L.M. Hough (Ed.), Handbook of industrial and organizational psychology, C.4. Palo Alto: Consulting Psychologists Press, p.769827.

Tüz, M.V. (2004). Değişim ve kaos ortamında işletme davranışı. İstanbul: Alfa Akademi. 
Usta, M.E. (2013). Okul yöneticilerinin pozitivist ve kaos yönetim anlayışlarını benimsemelerinin kendilerinin ve ögretmenlerin örgüt sel bağlllık düzeylerine etkileri. Yayınlanmamış doktora tezi, Fırat Üniversitesi, Elâzı̆̆.

Usta, M.E. (2017). Yönetim anlayışları ölçeğinin geliştirilmesi. Mukaddime, 8(2), 265-285.

Watts, D.M. (2009). Enabling school structure, mindfulness, and teacher empowerment: Test of a theory. Unpublished doctoral dissertation, The University of AlabamaTuscaloosa, Alabama.

Weick, K.E., \& Sutcliffe, K.M. (2001). Managing the unexpected: Assuring high performance in an age of complexity. San Francisco: Jossey-Bass.

Wu, J.H., Hoy, W.K., \& Tarter, C.J. (2013). Enabling school structure, collective responsibility and a culture of academic optimism: Toward a robust model of school performance in Taiwan. Journal of Educational Administration, 51(2), 176-193.

Yeloğlu, H.O. (2011). Türk toplumsal kültürünün örgüt yapılarına olan etkilerinin belirlenmesine yönelik bir çalışma. Sosyal Bilimler Araştırmaları Dergisi, 2(4), 153 170.

Y1ldırım, A.ve Açı1, Y. (2020). Okul yönetiminde yönetim süreçlerinin etkililiği ile örgütsel adalet arasındaki ilişki. Karamanoğlu Mehmetbey Uluslararası Eğitim Araştırmaları Dergisi, 2(2), 169-179.

Yılmaz, A.İ.ve Beycioğlu, K. (2017). Teachers' perceptions regarding bureaucratic structures in schools. Anadolu Üniversitesi Ĕ̆itim Fakültesi Dergisi, 1(2), 1-23.

Yoo, B., Donthu, N., \& Lenartowicz, T. (2011). Measuring Hofstede's five dimensions of cultural values at the individual level: Development and validation of CVSCALE. Journal of International Consumer Marketing, 23(3-4), 193-210.

Yukl, G. (2013). Leadership in organizations. New Jersey: Pearson, Prentice Hall. 


\title{
An Analysis of The Effectiveness of The Administrative Processes: A Multiple and Holistic Perspective in The Context of The Administrative Understanding, Bureaucratic Structure, and Cultural Values
}

\author{
Gülsüm SERTEL *, Süleyman KARATAŞ ${ }^{* *}$, Engin KARADAĞ $\breve{K}^{* * *}$
}

- Received: 16.10.2021 • Accepted: 18.12.2021 • Online First: 18.12.2021

\begin{abstract}
This study aims to reveal the effects of the administrative approach of educational institutions, bureaucratic structure, and cultural values on the administrative processes. The correlational design, one of the quantitative research methods, was employed in the study. The participants of the study are 418 teachers who were selected through the stratified sampling technique. They were working at public schools in the Pamukkale and Merkezefendi districts of Denizli. The data of the study were collected through the following four scales: "Effectiveness of the Administrative Processes," "Administrative Concepts," "Effectiveness of School Structure," and "Individual Cultural Values." The study's findings indicate that the administrative processes are highly correlated with the positivist administration approach and facilitating bureaucratic structure; it has a medium-level negative correlation with the obstructive bureaucratic structure and a low-level positive correlation with the chaotic administrative approach and avoidance from uncertainty. The multiple hierarchical regression analysis results indicate that the facilitating bureaucratic structure, positivist management approach, and long-term cultural values greatly affected the administrative processes. The effectiveness of administrative processes can be realized through an administrative approach in which long-term planning, a facilitating bureaucratic structure, and positivist and postmodern philosophy are intertwined. Other factors that may be effective in the administrative processes should be examined in future studies using different methods.
\end{abstract}

Keywords: effectiveness of the administrative processes, administrative approach, bureaucratic structure, cultural values

\section{Cited:}

Sertel, G., Karataş, S., \& Karadağ, E. (2022). An analysis of the effectiveness of the administrative processes: A multiple and holistic perspective in the context of the administrative understanding, bureaucratic structure, and cultural values. Pamukkale University Journal of Education, 55, 72-99.doi:10.9779.pauefd.1010888

\footnotetext{
* PhD Student, Akdeniz University/ Ministry of National Education Antalya, Turkey, gulsum_sertel@hotmail.com, ORCID ID: 0000-0002-1907-040X

** Assoc. Dr., Akdeniz University, Antalya, Turkey, skaratas@akdeniz.edu.tr, ORCID ID: 0000-0003-0002-2886 (Corresponding Author)

*** Prof. Dr., Akdeniz University, Antalya, Turkey, enginkaradag@akdeniz.edu.tr, ORCID ID: 0000-0002-9723-3833
} 


\section{Introduction}

Today, sudden and great changes in different areas such as technology, economy, politics, communication, and socio-cultural values affect managerial roles, jobs, and job processes (Dess \& Picken, 2000). The changes in demographic patterns due to globalization have expanded the necessity of understanding the factors that affect the nature of administration and the related processes and managing people with different values, beliefs, and expectations at the national and global levels. Given that the leadership perception and administrative approaches have changed as a result of the paradigms and that organizations have evolved from traditional groups to complex and flexible patterns as a result of the current needs (Palmberg, 2009), the philosophy on which administrators' understanding about management is based, and the reflections of their administrative practices on the bureaucratic structure and their effects on administrative processes and outputs should be examined. Therefore, within the organizations, the structure, individuals, cultural values, political practices, and administrative approach affect the performance of employees (Hoy \& Miskel, 2010), and these also have effects on the administrative processes. Based on this framework, this study aims to reveal the effects of the administrative approach of the educational institutions, bureaucratic structure, and cultural values on the administrative processes.

\section{Effectiveness of administrative processes}

Management is the process of achieving organizational goals through people and resources effectively and efficiently (Aydın, 2018; Bateman \& Snell, 2013; Bursalığlu, 2015; Robbins et al., 2013). The administrative process is a process in which the functions of transforming, operating, sustaining, and improving the organization are carried out, and it includes a flow, change, and formation in line with the organizational objectives (Başaran, 2008; Bursalığlu, 2015). In short, the administrative process is a whole that covers the comprehensive and multifaceted activities carried out in a systematic, conscious, and organized manner to fulfill the organization's objectives effectively and efficiently.

The administrative processes were first scientifically discussed by $\mathrm{H}$. Fayol and categorized into five dimensions: planning, organizing, ordering, coordination, and control (Fayol, 1916). Gregg (1957) argues that the administrative processes are unity actions that are consisted of seven interrelated elements, namely making decisions, planning, organizing, communication, effects, coordination, and evaluation. Research suggests that the elements of the administrative processes are interrelated and compose a whole (Akyol, 2013; Aydin, 
2018; Erdoğan, 2003). Aydın (2018) argues that none of these elements have to mean themselves, but each has an organic relationship composing a whole. On the other hand, it is seen that there are very few studies that deal with the administrative processes in the field of education, and instead, these studies deal with specific issues. More specifically, such studies analyze the administrative processes of organizational fairness (Akyol, 2013; Aç1l, 2020); their mechanisms (Aydın, 2019; Aydoğan, 1988; Büte \& Balc1, 2010); the development of scales (Gül, 2017); emotion management (Çoruk, 2012) and the emotional, social and mental capacities of the administrators (Summak \& Yazgan, 2007). The related studies emphasize the significance of analyzing the factors affecting the administrative processes in education in terms of administrative and organizational efficiency, leadership, and organizational behavior.

\section{Bureaucratic Structure and Administrative Processes}

Organizational structure refers to the relationships between the division of labor and coordination in the organization (Mintzberg, 2014) and affects the forms, mechanisms, and coherence of all organizational activities (Griffin \& Moorhead, 2014). One of the factors that affect the functioning of the administrative processes is the bureaucratic structures of organizations. Schools are formal organizations with many bureaucratic structure features (Buluç, 2009; Hoy \& Miskel, 2010; Messick, 2012). The importance of bureaucratic structure in analyzing the organizational and administrative behavior at schools has been investigated by many scholars (Abbott, 1965; Abbott \& Caracheo, 1988; Corwin \& Borman, 1988; Firestone \& Herriot, 1981; Miles, 1965). For instance, Abbott (1965) described the school organization as a highly developed bureaucracy. Hoy and Sweetland (2000, 2001) examined the educational organizations as a facilitating (authorizing) bureaucratic structure and a hindering bureaucratic structure depending on their empowering and obstructive features in terms of centralization (leveling of authority) and shaping (rules, regulations, procedures, etc.).

Studies concerned with the schools have concluded that the structural characteristics of schools differ from each other (Hoy, 2003; Hoy \& Miskel, 2010; Hoy \& Sweetland, 2000,2001; Sinden et al., 2004). However, it is necessary to create a facilitating school structure instead of an obstructive one (Hoy \& Sweetland, 2001). Because the facilitating bureaucratic structure at schools affects the collaboration between teachers positively and significantly contributes to academic success (Weick \& Sutcliffe, 2001). In addition, in a facilitating school structure, the school administrators and teachers cooperate, decide 
together to solve the problems, and the school administration supports the structures in which the teachers can work more effectively (Wu et al., 2013). Therefore, the bureaucratic structure perceived by the teachers affects their attitudes and behaviors towards the school. It is also one of the important factors affecting management processes.

\section{Administrative Approach and Administrative Processes}

In organizations, the administrators' assumptions about the nature of human beings, and their perspectives on humans are determinants of their administrative and functioning processes (Aydın, 2018). In this study, the administrative approach of the school administrators is discussed in terms of both positivist and postmodern administrative approaches. In the positivist management approach, the employee is seen as an organizational entity that shows harmony and obedience, acts based on the pre-established rules, is part of a plannedprogrammed hierarchy, does not take any initiative, and is forbidden to establish informal relations (Bulaç, 1990). On the other hand, the administrator is not a leader and owes his success to his authority, giving orders, asking for obedience, and trying to restore the balance that is constantly disturbed to maintain the status quo (Aç1kalın, 1995). At schools with a positivist management approach, the administrator owns authority and power and uses this power as a bureaucratic and central pressure tool consisting of systematic rules. The values, beliefs, expectations, and choices of individuals are ignored (Aslanargun, 2007). Therefore, the positivist administration approach, which has a structuralist and bureaucratic tendency, is criticized for being goal-oriented, having a rational decision-making process, keeping the structure above everything, gathering the hierarchy in the top management, and neglecting the individual in the group (Bush, 1995). Therefore, the postmodern management approach has emerged due to the criticisms against the positivist modern management approach due to its neglect of individual values.

One of the most important contributions of the postmodern understanding towards management is that it brings the leadership phenomenon to the forefront instead of the concepts such as the manager and the school administrator, which are seen as extensions of the positivist understanding. The school administrator, a leader at schools where the postmodern management approach is dominant, thinks about long-term actions, can look at events critically and skeptically, and employs non-rational processes such as motivation by emphasizing human values (Aslanargun, 2007). Given that these two administration approaches are interwoven, it is an inevitable fact that the managers and administrators of huge modern organizations, which have the characteristics of development and complexity, 
should have the ability to manage this complexity and chaos (Demirtaş, 2006). Therefore, it is thought that examining the management understanding of administrators at schools is an effective way to be informed about the functioning of management processes, and the perspectives of the organizations concerning people and society are influential on the organizational outputs.

\section{Cultural Values and Administrative Processes}

Culture can be defined broadly as system meanings that differentiate one group from the others (Aydın, 2018; Robbins, 1998). Hofstede defines culture as collective mental programming acquired during the lifetime and distinguishes a group of people from the others, affecting social life (Hofsede, 1980a, 1980b, 2001; Hofstede et al.,2010). The author emphasizes that culture consists of the common cultural components of the nation in which individuals live and that people in different countries have different cultural values and conceptualizes these differences as national culture (Hofstede, 2001). In the present study, the cultural values of the educational organizations are analyzed using the following dimensions of Hofstede's theory on cultural values: power distance, avoidance from uncertainty, individualism/collectivism, masculinity/femininity (Hofstede, 1980a), and short/long term efficacy (Hofstede \& Bond, 1988; Hofstede et al.,2010; Hofstede, 2001).

Power distance refers to the belief about the appropriateness of power distribution in a society (Steers et al.,2010) and to the level of agreement about the unfair distribution of power in organizations and institutions (Hofstede, 1980a; Yukl, 2013). Avoidance from uncertainty is about the level of perceived threat and anxiety among individuals in the face of uncertainty or strange events (Hofstede, 2001). In individualistic cultures, individuals act with a sense of "I", their needs and interests, and autonomy is at the forefront; individual rights are more important than social responsibilities (Dickson et al.,2003; Gelfand et al., 2004; Hofstede, 1980b; Scarborough, 1998; Steers et al.,2010). In collectivist cultures, group interests are much more significant than individuals (Kluckhohn \& Strodtbeck, 1961; Steers et al.,2010; Triandis, 1995). In such cultures, group loyalty is an important element of an individuals' self-identity, and group loyalty is an important value (Yukl, 2013) and individuals act with a sense of "we" (Hofstede, 1980b). In masculine cultures, individuals are assertive, ambitious, competitive, give importance to wealth and money, and are focused on individual and financial success (Hofstede, 1980a). In feminine cultures, individuals are more modest and sensitive, and strong social ties, quality of life, and wealth of others are valued (Hofstede, 1980a,2001). Long/short-term efficacy is about the perspective on time, 
goals, planning, job, life, and relationships. In long-term efficacy cultures, future orientation, dedication, hard work, and savings are valued, while in short-term efficacy cultures, past and present orientation, traditions, and social responsibilities are valued (Hofstede et al.,2010; Steers et al.,2010).

Cultural values make significant contributions to the understanding of the culture of organizations with different structures in the society, the individuals with different cultural values and events in these organizations (Hofstede, 1983), and the shaping of goals and objectives, decision-making, structure, and effective motivation tools in organizations (Hofstede, 1981). In educational institutions, the administrators' awareness about cultural values and the transformation of cultural values into an effective source of motivation in line with the goals of the organization will increase both the impact of administrative processes and organizational effectiveness.

\section{Aim}

This study aims to reveal the effects of the administrative approach of the educational institutions, bureaucratic structure, and cultural values on the administrative processes based on the views of teachers working at public schools. The hypotheses developed in the study are as follows:

$\mathrm{H}_{1}$ : Facilitating bureaucracy has a positive effect on the effectiveness of administrative processes, while obstructive bureaucracy harms the effectiveness of administrative processes.

$\mathrm{H}_{2}$ : There is a significant correlation between the administrative approach and administrative processes.

$\mathrm{H}_{3}$ : There is a significant correlation between cultural values and administrative processes.

$\mathrm{H}_{4}$ : When the administrative approach's demographical characteristics of teachers and schools are controlled, cultural values and schools' facilitating bureaucratic structure affect the administrative processes at a high level. 


\section{Method}

\section{Design of the study}

The correlational design was used in this quantitative study that examines the relationship between the effectiveness of the administrative processes, administrative understanding, bureaucratic structure, and cultural values. This design aims at uncovering whether there is a relationship between two or more variables and/or the degree of the relationship (Fraenkel \& Wallen, 2006; Karasar, 2017).

\section{Samples}

Seven thousand five hundred ninety-eight teachers were working at 265 public educational institutions in the Pamukkale ve Merkezefendi distractions of Denizli province in 2019-2020 based on the data of the strategical development unit of the provincial national education directorate. Considering the generally accepted 95\% confidence level and 5\% margin of error, the minimum number of participants was found to be 366 (Field, 2009). The data collection tools were administered to 500 teachers, and 462 scales were returned. However, only 418 correctly filled the scales. The stratified sampling technique, which is one of the probability sampling techniques, was used to determine the number of participants. The types of the schools (primary school-middle school-high school) were taken into account while stratifying the participants. Through the stratified sampling method, the ratio of the subgroups in the non-homogeneous study universe was found (Büyüköztürk et al.,2008), which increased the ability of the subgroups to represent the participant group (Balc1, 2018).

The teachers participating in the research; $67.7 \%$ female, $32.3 \%$ male; $84.2 \%$ are undergraduate graduates, and $15.8 \%$ are graduates. In addition, $8.4 \%$ of teachers are less than 5 years, $16.7 \%$ 6-10 years, 20.6\% 11-15 years, 27.8\% 16-20 years, 13.4\% 21-25 years and $13.2 \%$. si is more than 26 years senior. And $24.6 \%$ of the teachers are in basic education, $37.8 \%$ verbal, $19.6 \%$ numerical, $6.7 \%$ vocational-technical and $11.2 \%$ art-sports. Of the schools in the study, $25.8 \%$ are primary schools, $43.5 \%$ secondary school, and $30.6 \%$ high school. In addition, $25.6 \%$ of the schools have low socio-economic status, $60.5 \%$ medium, and $13.9 \%$ high socio-economic level. And $28.5 \%$ of the schools have 1-20 teachers, $19.6 \%$ have $21-40$ teachers and $51.9 \%$ have 41 or more teachers. In addition, $7.7 \%$ of the schools have one administrator, $29.4 \%$ have two administrators, $20.8 \%$ have three administrators, and $42.1 \%$ have four or more administrators. 


\section{Data collection tools}

The data of the study were collected using several scales, each of which is introduced as follows:

\section{The administrative approach scale}

This scale was developed by Usta (2017), and it has two dimensions (chaotic administrative approach and positivist administrative approach) and twenty-three items. Usta (2017) reported the reliability coefficient of the scale as $(\alpha) .948$ (for dimensions one and two, it is .970 and .888 , respectively). It is a 5-point Likert-type scale. In the present study, the Barlett test results of the scale were found to be significant. Its Kaiser-Meyer-Olkin (KMO) value was.960, and the reliability coefficient was found to be .984 (it is .982 and .943 for the dimensions, respectively).

\section{The facilitating school structure Scale}

The scale was developed by Hoy and Sweetland (2000) and was adapted by Buluç (2009) into Turkish. The psychometric characteristics of the scale were reanalyzed by Özer and Dönmez (2013). It is a two-dimension (facilitating bureaucracy and obstructive bureaucracy) scale with twelve items. Özer and Dönmez (2013) found the reliability coefficient $(\alpha)$ of the dimension "facilitating bureaucracy" to be .774 and of the dimension "obstructive bureaucracy" to be 806 . It is a 5-point Likert scale. In the present study, the result of the Barlett Test is found to be significant. Its Kaiser-Meyer-Olkin (KMO) value was found to be .834 , and the reliability coefficient for the dimension "facilitating bureaucracy" was .833 , and that for the dimension "obstructive bureaucracy" was .883.

\section{The individual cultural values scale}

In order to reveal the cultural values, the scale of the individual cultural values developed Hofstede was employed in the study. The scale was redesigned by Yoo, Donthu, and Lenartowicz (2011) to include the individual dimension of the cultural values and was adapted into Turkish by Saylık (2019). It is a 5-point Likert type scale, with five dimensions (power distance, avoidance from uncertainty, collectivism, long-term efficacy, masculinity) and twenty-six items. Saylik (2019) found the reliability coefficient $(\alpha)$ of the scale as .80 (for the dimensions, it was found to be $.63, .82, .87, .85$, and .82, respectively). In the present study, the result of the Barlett Test was found to be significant. Its Kaiser-MeyerOlkin (KMO) value was found to be .833 , and its reliability coefficient was found to be .858 (for the dimensions, it was found to be $.883, .856, .845, .879, .838$ ve .881 , respectively). 
The efficacy of the administrative processes scale

In order to evaluate the use of the administrative processes by the school administrators, the scale of the efficacy of the administrative processes developed by Gül (2017) was employed. The scale has only one dimension and thirty-five items and is a 5-point Likert-type scale. Gül (2017) reported the reliability coefficient of the scale $(\alpha)$ as .982 . In the present study, the results of the Barlett Testi were found to be significant. The Kaiser-Meyer-Olkin (KMO) value was .974 , and its reliability coefficient was found to be .992 .

\section{Data collection procedure and data analysis}

The data collection tools introduced above were administrated to the participants at the schools where they were working. The data collected were examined using the SPSS 23.0. The data were first analyzed in terms of the normality distribution. In the study, the skewness values of the data are "- 1.175 " and " 0.817 ”; The kurtosis values are between "$.867 "$ and "1.408". The skewness and kurtosis values of the data were found to range

between $\pm 1,5$. It was also found that the data had a normal distribution (Tabachnick \& Fidell, 2013), which requires the parametric tests in the data analysis. The reliability of the collected data was analyzed using the Cronbach's Alpha internal consistency coefficient, the demographic variables were analyzed by percentage and frequency analysis, the arithmetic mean and standard deviation values of the variables were analyzed using the descriptive statistics. The Pearson correlation analysis analyzed the direction and level of the correlations between the variables. The correlation coefficient values are assumed to be high for the range of $0.70-1.00$, medium for the range of $0.70-0.30$, and low for the range of 0.30 0.00 (Büyüköztürk, 2016; Roscoe, 1975). In the study, the multiple hierarchical regression analysis was used to examine the effects of both categorical and continuous variables simultaneously and to see the final variables' combined effect in the final model. In this way, the effects of independent variables (administrative understanding, school structure, cultural values) on the dependent variable (effectiveness of the administrative processes) were examined.

To determine whether the multicollinearity assumption is provided in the models created within the scope of the analysis, the values from the collinearity statistics are taken into consideration. The study observed that the tolerance values were greater than "..18" and the VIF values were less than "5.33". The results of this analysis show that tolerance values are higher than 0.10 (Çokluk et al.,2018; Field, 2009; Mertler and Vannatta, 2005) and that 
the VIF (Variance Inflation Factor) values are equal to 10, but not higher than 10 (Webster, 1992 act. Albayrak, 2005) (Tolerance=1/VIF, Tolerance $\left.>1-\mathrm{R}^{2}\right)$. It is also found that there is no multi-linear correlations among the independent variables and that the use of the unstandardized beta (B) coefficients is appropriate for the formulas in the regression models.

In the multiple hierarchical regression analysis, the first step was to transform the categorical variables about the characteristics of the participants and schools into dummy variables that were employed in the analysis. The dummy variables about the teacher characteristics are coded as follows: gender=male1; educational background=undergraduate 1 ; teaching field=basic education 1 and teaching experience $=1-5$ years. The codes of the variables about the schools are as follows: school type=primary school1; the number of teachers $=1-20$ teachers; the number of school administrators $=$ school administrator1 and socio-economic status of the students=low 1. The characteristics of the participants were included in the first model and those of the schools in the second model. Then, the dummy variables were controlled. The third model contained the structure of the schools, the fourth model the administrative approach of the school administrators, and the fifth model the individual cultural values, to see the ultimate effects of the variables that had a significant effect. These variables were included in the sixth model of the analysis. The analysis results did not consider the beta value $(\beta)$ but the unstandardized beta $(B)$ value.

The size of the regression coefficients was analyzed. However, in the multicollinearity analyses, the effect size was analyzed using Cohen's formula, $f^{2}=\left(\mathrm{r}_{2}{ }^{2}\right.$ $\left.\mathrm{r}_{1}^{2}\right) /\left(1-\mathrm{r}_{1}^{2}\right)$, suggested by Aiken and West (1991). Here $\mathrm{r}_{1}^{2}$ is $\mathrm{R}^{2}$ (R square) belonging to the second step of the hierarchical regression analysis, and $\mathrm{r}_{2}^{2} \mathrm{~s} \mathrm{R}^{2}$ ( $\mathrm{R}$ square) belonging to the third step of the hierarchical regression analysis. The formula suggests that $f^{2}=0,02$ indicates small effect, $f^{2}=0,15$ indicates medium effect, and $f^{2}=0,26$ indicates high effect (Cohen et al.,2003).

\section{Findings}

\section{Findings on descriptive statistics and correlational analysis}

The descriptive statistics of the variables in the study and the correlation matrix values showing the direction and level of the relations between the variables are given in Table 1 . 
Table 1. Descriptive Statistics and Correlation Matrix of the Variables of the Administrative Approach, Individual Cultural Values, School Structure, Effectiveness of the Administrative Processes $(N=418)$

\begin{tabular}{|c|c|c|c|c|c|c|c|c|c|c|c|c|}
\hline & $\mathrm{CA}$ & PA & $\overline{\mathbf{A A}}$ & PD & $\mathrm{AFU}$ & $\mathrm{C}$ & LTE & $\mathrm{M}$ & ICV & $\mathrm{FB}$ & OB & EAP \\
\hline $\mathbf{C A}$ & - & & & & & & & & & & & \\
\hline PA & $.34^{* *}$ & - & & & & & & & & & & \\
\hline $\mathbf{A A}$ & $.91^{* * *}$ & $.33^{* *}$ & - & & & & & & & & & \\
\hline PD & $.64^{* *}$ & $.11^{*}$ & $.54^{* *}$ & - & & & & & & & & \\
\hline AFU & $.66^{* *}$ & $.35^{* *}$ & $.60^{* *}$ & .09 & - & & & & & & & \\
\hline C & $.79^{* *}$ & $.28^{* *}$ & $.76^{* *}$ & $.18^{* *}$ & $.43^{* *}$ & - & & & & & & \\
\hline LTE & $.31^{* *}$ & $.23^{* *}$ & $.48^{* *}$ & $-.20^{* *}$ & $.47^{* *}$ & $.44^{* *}$ & - & & & & & \\
\hline $\mathbf{M}$ & $.21^{* *}$ & .02 & $.50^{* *}$ & $.32^{* *}$ & -.06 & $.13^{* *}$ & -.10 & - & & & & \\
\hline ICV & $.91^{* *}$ & $.33^{* *}$ & $1.00^{* *}$ & $.54^{* *}$ & $.60^{* *}$ & $.76^{* *}$ & $.48^{* *}$ & $.50^{* *}$ & - & & & \\
\hline FB & $.31^{* *}$ & $.76^{* *}$ & $.33^{* *}$ & $.13^{* *}$ & $.31^{* *}$ & $.23^{* *}$ & $.19^{* *}$ & $.12^{*}$ & $.33^{* *}$ & - & & \\
\hline OB & -.01 & $-.43^{* *}$ & .06 & $.23^{* *}$ & $-.26^{* *}$ & -.05 & $-.21^{* *}$ & $.35^{* *}$ & .06 & $-.47^{* *}$ & - & \\
\hline EAP & $.30^{* * *}$ & $.86^{* * *}$ & $.28^{* * *}$ & $.16^{* * *}$ & $.25^{* *}$ & $.22^{* *}$ & $.12^{*}$ & .08 & $.28^{* *}$ & $.79^{* * *}$ & $-.43^{* *}$ & - \\
\hline $\bar{X}$ & 3.25 & 3.78 & 3.85 & 2.19 & 3.88 & 3.62 & 4.32 & 2.64 & 3.40 & 3.74 & 2.51 & 3.85 \\
\hline Sd & .59 & .92 & .55 & .96 & .73 & .83 & .60 & 1.16 & .49 & .78 & .96 & .96 \\
\hline
\end{tabular}

$\overline{\boldsymbol{X}}$-Mean, Sd-Standard Deviation, CA-Chaotic Administrative, PA- Positivist Administrative, AA-Administrative Approach, PD-Power Distance, AFU-Avoidance From Uncertainty, CCollectivism, LTE-Long-Term Efficacy, M-Masculinity, ICV-Individual Cultural Values, FB-Facilitating Bureaucracy, OB-Obstructive Bureaucracy, EAP-Effectiveness of The Administrative Processes

As shown in Table 1, the participants have a higher level of the positivist administrative approach and a medium level of the chaotic administrative approach. They perceived long-term efficacy at the higher level and the avoidance from certainty and collectivism at a high level. The levels of the participants' perception of masculine value are found to be at a medium level. Their perceptions about power distance are at the lower level. At their schools, the participants perceived the facilitating bureaucratic structure at higher levels and the obstructive bureaucratic structure at lower levels. They also reported that the effects of the administrative processes are at higher levels. 
The results of the correlational analysis indicate that the efficiency of the administrative processes has a positive and high correlation with the positivist administrative approach. The efficiency of the administrative processes has a positive and low correlation with the avoidance from uncertainty, power distance, and long-term efficacy of the individual cultural values. The effectiveness of the administrative processes at the schools is found to have a positive and high correlation with the facilitating bureaucratic structure and a negative and medium correlation with the obstructive bureaucratic structure.

Findings on hierarchical multiple regression showing the prediction of the effectiveness of management processes

The results of the multiple hierarchical regression analysis performed to determine the effects of the independent variables that predict the effectiveness of the administrative processes are given in Table 2.

Table 2. Hierarchical Multiple Regression Analysis Results Showing the Effect of Independent Variables on the Efficiency of the Administrative Processes ( $N=418)$

\begin{tabular}{|c|c|c|c|c|c|c|c|c|c|c|}
\hline & & & ficienc & of th & Administ & ative $P_{1}$ & ocesses & & & \\
\hline & Predictive & & Todel 1 & & & Model 2 & & & odel 3 & \\
\hline & Variables & $\bar{B}$ & S.H. & $\bar{\beta}$ & $\bar{B}$ & S.H. & $\beta$ & $B$ & S.H. & $\beta$ \\
\hline & Constant & 125.718 & 4.439 & & 125.660 & 4.619 & & 16.905 & 7.770 & \\
\hline 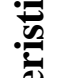 & Male & -2.754 & 3.597 & -.038 & -3.967 & 3.650 & -.055 & -1.017 & 2.285 & -.014 \\
\hline$\underset{\overparen{E}}{\tilde{E}}$ & $\begin{array}{l}\text { Under } \\
\text { graduate1 }\end{array}$ & $10.136 *$ & 4.524 & .110 & $10.849 *$ & 4.598 & .117 & 5.390 & 2.880 & .058 \\
\hline 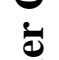 & Basic & 2.556 & 3.869 & .033 & 20.016 & 11.039 & .256 & -.079 & 7.067 & -.001 \\
\hline ల్ & Education1 & & & & & & & & & \\
\hline$\stackrel{\varpi}{\oplus}$ & $\begin{array}{l}\text { 1-5 Years } \\
\text { seniority }\end{array}$ & 7.387 & 6.058 & .061 & 11.925 & 6.563 & .098 & -3.851 & 4.114 & -.032 \\
\hline$\overbrace{\tilde{y}}^{\tilde{e}}$ & $\begin{array}{l}\text { Primary } \\
\text { School1 }\end{array}$ & & & & -15.402 & 11.084 & -.200 & 3.542 & 7.044 & .046 \\
\hline 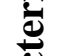 & Low 1 & & & & 3.161 & 4.235 & .041 & 2.173 & 2.625 & .028 \\
\hline שֶׁ: & SES & & & & & & & & & \\
\hline$\stackrel{\frac{\pi}{7}}{1)}$ & $1-20$ & & & & -5.463 & 5.776 & -.073 & -6.737 & 3.588 & -.090 \\
\hline$\frac{0}{0}$ & Teachers & & & & & & & & & \\
\hline$\frac{2}{0}$ & 1 & & & & -1.403 & 6.534 & -.011 & 2.900 & 4.072 & .023 \\
\hline$y$ & Administrator & & & & & & & & & \\
\hline
\end{tabular}




\begin{tabular}{|c|c|c|c|c|c|c|}
\hline \multirow[t]{2}{*}{$\overline{\mathbf{B S}}$} & \multicolumn{3}{|l|}{ FB } & $5.402 * * *$ & .253 & .748 \\
\hline & OB & & & $-.485 *$ & .211 & -.083 \\
\hline \multirow[t]{2}{*}{$\overline{\mathbf{A A}}$} & $\mathrm{CA}$ & & & & & \\
\hline & PA & & & & & \\
\hline \multirow[t]{4}{*}{$\overline{\mathrm{ICV}}$} & PD & & & & & \\
\hline & $\mathrm{AFU}$ & & & & & \\
\hline & LTE & & & & & \\
\hline & M & & & & & \\
\hline \multicolumn{2}{|l|}{$\overline{\mathbf{R}}$} & .138 & .177 & & & .794 \\
\hline \multicolumn{2}{|l|}{$\mathbf{R}^{2}$} & .019 & .031 & & & .630 \\
\hline \multicolumn{2}{|c|}{ Adjusted $\mathbf{R}^{2}$} & .010 & .012 & & & .621 \\
\hline \multicolumn{2}{|l|}{$\Delta \mathbf{R}^{2}$} & .019 & .012 & & & .598 \\
\hline
\end{tabular}

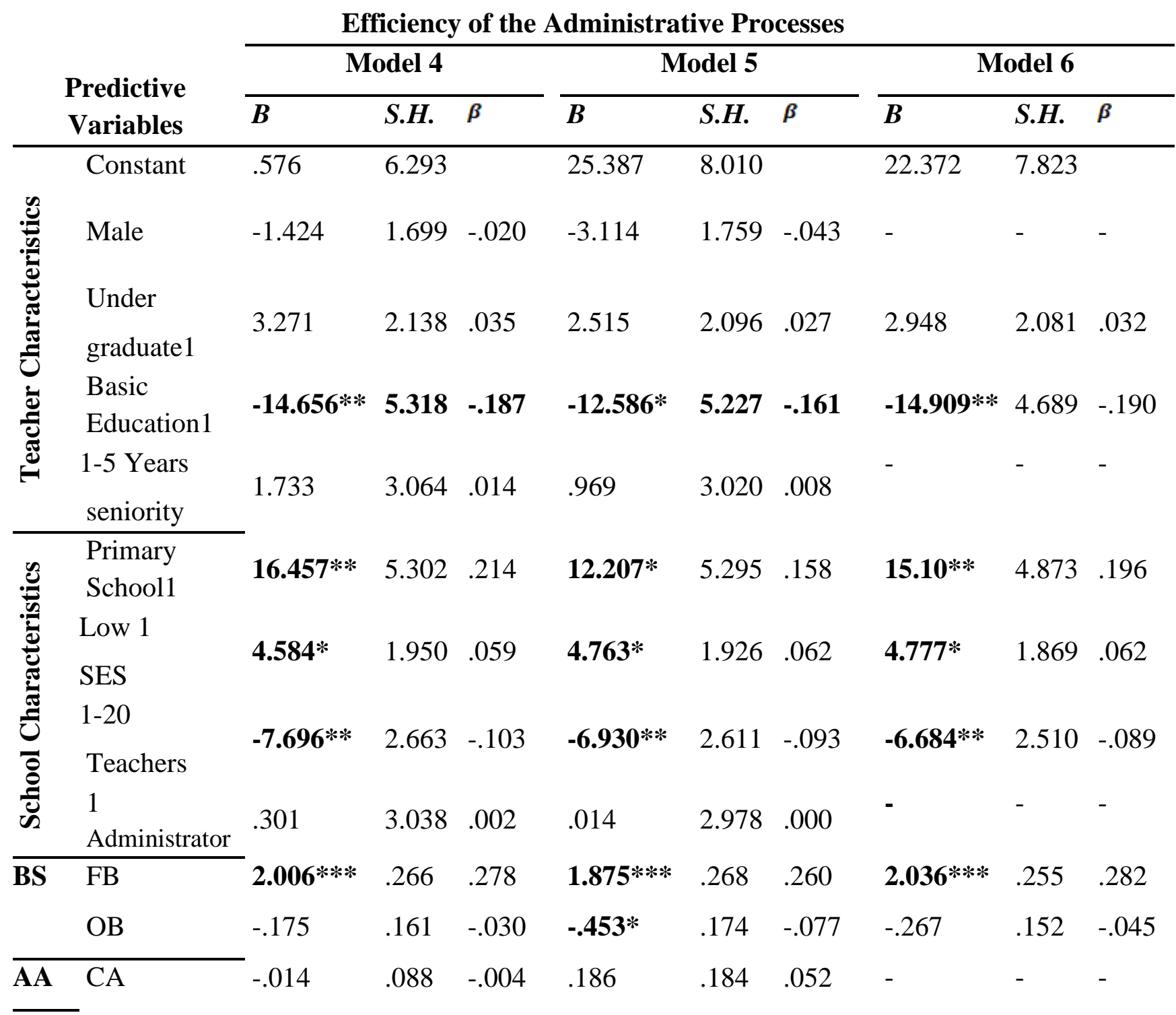




\begin{tabular}{|c|c|c|c|c|c|c|c|c|c|c|}
\hline & PA & $3.413 * * *$ & .189 & .654 & $3.481 * * *$ & .185 & .667 & $3.474 * * *$ & .182 & .665 \\
\hline \multirow[t]{4}{*}{$\overline{\mathrm{ICV}}$} & $\mathrm{PD}$ & & & & .096 & .280 & .014 & - & - & - \\
\hline & $\mathrm{AFU}$ & & & & -.640 & .343 & -.069 & - & - & - \\
\hline & LTE & & & & $-.760 * *$ & .262 & -.081 & $-.904 * * *$ & .216 & -.096 \\
\hline & $\mathrm{M}$ & & & & .258 & .198 & .035 & - & - & - \\
\hline \multicolumn{3}{|l|}{$\begin{array}{l}\mathbf{R} \\
\end{array}$} & & .893 & & & .900 & & & .897 \\
\hline \multicolumn{3}{|c|}{$\mathbf{R}^{2}$} & & .798 & & & .810 & & & .805 \\
\hline \multicolumn{3}{|c|}{ Adjusted $\mathbf{R}^{2}$} & & .792 & & & .803 & & & .801 \\
\hline \multicolumn{3}{|c|}{$\Delta \mathbf{R}^{2}$} & & .168 & & & .013 & & & .805 \\
\hline
\end{tabular}

SES-Socio-Economic Status, FB-Facilitating Bureaucracy, OB-Obstructive Bureaucracy, CA-Chaotic Administrative, PA-Positivist Administrative, PD-Power Distance, AFUAvoidance From Uncertainty, LTE-Long-Term Efficacy, M-Masculinity, BS-Bureaucratic Structure, AA-Administrative Approach, ICV-Individual Cultural Values

In the first model, it is found that the teacher characteristics (gender=male1, educational background=undergraduate1, teaching field=basic education1, teaching experience $=1-5$ years) do not have any significant effect on the effectiveness of the administrative processes at the schools $\left[\mathrm{R}^{2}=.019 ; \mathrm{p}=.093>.05\right]$. However, of these characteristics, the educational background [educational background=undergraduate1; $\mathrm{B}=10.136 ; \mathrm{p}<0.05]$ is found to have a significant effect on the effectiveness of the administrative processes at the schools. In short, the teacher characteristics generally do not significantly affect the effectiveness of the administrative processes at the schools.

In the second model, it is found that the school characteristics (school type=primary school1, socio-economic status=low, the number of teachers $=1-20$ teachers, the number of school administrators $=1$ school administrator) do not have any significant effect on the effectiveness of the administrative processes at the schools $\left[\mathrm{R}^{2}=.031 ; \Delta \mathrm{R}^{2}=.012\right.$; $\mathrm{p}=.273>.05$ ]. However, in the second model, the educational background [educational background=undergraduate $1 ; \mathrm{B}=10.849 ; \mathrm{p}=.019<0.05]$ is found to have a significant effect on the effectiveness of the administrative processes at the schools. The effect size of the second model is found to be $f^{2}=\left(\mathrm{r}_{2}{ }^{2}-\mathrm{r}_{1}{ }^{2}\right) /\left(1-\mathrm{r}_{1}{ }^{2}\right)=[(0.031-0.019) /(1-0.019)]=0.01$ which is at a low level. In short, the school characteristics generally do not significantly affect the effectiveness of the administrative processes at the schools. 
In the third model, the variables about the school structures (facilitating bureaucracy and obstructive bureaucracy) are found to significantly affect the effectiveness of the administrative processes at the schools $\left[\mathrm{R}^{2}=.630 ; \Delta \mathrm{R}^{2}=.598 ; \mathrm{p}=.000<0.001\right]$. It accounts for $63 \%$ of the total variance. In short, both facilitating bureaucracy $[B=5.402 ; p=.000<0.001]$ and obstructive bureaucracy $[\mathrm{B}=-.485 ; \mathrm{p}=.022<0.05]$ have significant contributions to the effectiveness of the administrative processes at the schools. The former has positive contributions, but the latter's contributions are negative. Therefore, a one-point increase in the facilitating bureaucracy at the schools leads to a 5,402 increase in their administrative processes. In addition, a one-point increase in the obstructive bureaucracy at the schools leads to 0,485 decreases in their administrative processes. The school structure accounts for $60 \%$ of the total variance $\left[\Delta \mathrm{R}^{2}=0.598 ; \mathrm{p}=.000<0.001\right]$. The effect size of the third model is high and found to be $f^{2}=\left(\mathrm{r}_{2}^{2}-\mathrm{r}_{1}^{2}\right) /\left(1-\mathrm{r}_{1}^{2}\right)=[(0.630-0.031) /(1-0.031)]=0.62$. The analysis of the third model indicates that an increase in the facilitating bureaucracy at the schools improves the effectiveness of the administrative processes.

In the fourth model, the variables about the administrative approach of the school administrators (chaotic administrative approach and positivist administrative approach ) are found to have a significant effect on the effectiveness of the administrative processes at the schools $\left[\mathrm{R}^{2}=.798 ; \Delta \mathrm{R}^{2}=.168 ; \mathrm{p}=.000<0.0001\right]$. These variables produced the level of the accounted total variance to $79.8 \%$. In addition, the following have a significant effect on the effectiveness of the administrative processes at the schools: teaching field [teaching field=basic education; $\mathrm{B}=-14.656 ; \mathrm{p}=.006<0.01$ ], school type [school type=primary school1; $\mathrm{B}=16.457 ; \mathrm{p}=.002<0.01$ ], socioeconomic status [socioeconomic status=low; $\mathrm{B}=4.584$; $\mathrm{p}=.019<0.05$ ], the number of teachers [number of teachers $1=1-20$ teachers; $\mathrm{B}=-7.696$; $\mathrm{p}=.004<0.01]$, facilitating bureaucracy $[\mathrm{B}=2.006 ; \mathrm{p}=.000<0.001]$ and positivist administrative approach $[\mathrm{B}=3.413 ; \mathrm{p}=.000<0.001]$. This model accounts for $16,8 \%$ of the total variance $\left[\Delta \mathrm{R}^{2}=0.168 ; \mathrm{p}=.000<0.001\right]$. the effect size of the model is found to be high $f^{2}=\left(\mathrm{r}_{2}^{2}-\mathrm{r}_{1}^{2}\right) /\left(1-\mathrm{r}_{1}^{2}\right)=[(0.798-0.630) /(1-0.630)]=0.45$. The results of the analysis about this model suggest that both facilitating bureaucracy and positivist administrative approaches are influential on the administrative processes of schools.

In the fifth model, the variables about the individual cultural values (power distance, avoidance from uncertainty, long-term efficacy, and masculinity) are found to have a significant effect on the effectiveness of the administrative processes at the schools $\left[\mathrm{R}^{2}=.810 ; \Delta \mathrm{R}^{2}=.013 ; \mathrm{p}=.000<0.001\right]$ and these variables produced the level of the accounted 
total variance to $81 \%$. In addition, the following have a significant effect on the effectiveness of the administrative processes at the schools: teaching field [teaching field =basic education $1 ; \mathrm{B}=-12.586 ; \mathrm{p}=.016<0.05$ ], school type [school type=primary school; $\mathrm{B}=12.207 ; \mathrm{p}=.022<0.05$ ], socioeconomic status [socioeconomic status=low; $\mathrm{B}=4.763$; $\mathrm{p}=.014<0.05$ ], the number of teachers [the number of teachers $=1-20$ teachers; $\mathrm{B}=-6.930$; $\mathrm{p}=.008<0.01]$, facilitating bureaucracy $[\mathrm{B}=1.875 ; \mathrm{p}=.000<0.001]$, obstructive bureaucracy $[\mathrm{B}=-.453 ; \mathrm{p}=.010<0.05]$, positivist administrative approach $[\mathrm{B}=3.481 ; \mathrm{p}=.000<0.001]$ and long-term efficacy $[\mathrm{B}=-.760 ; \mathrm{p}=.004<0.01]$. This model accounts for 1,3 of the total variance $\left[\Delta \mathrm{R}^{2}=0.013 ; \mathrm{p}=.000<0.001\right]$. The effect size of the fifth model is found to be high, $f^{2}=\left(r_{2}^{2}-r_{1}^{2}\right) /\left(1-r_{1}^{2}\right)=[(0.810-0.798) /(1-0.798)]=0.06$. The results of the analysis about this model indicate that facilitating bureaucracy, a positivist administration approach, and longterm efficacy as a cultural value have significant effects on the administrative processes.

In the sixth model, those variables which have a significant effect on the efficiency of the administrative processes (educational background=undergraduate, teaching field=basic education, school type=primary school, socio-economic status=low, the number of teachers $=1-20$ teachers, facilitating bureaucracy, obstructive bureaucracy, positivist administration approach, and long term efficacy) are reexamined in the regression analysis. The variables indicated their significant effects on the administrative efficacy in this model, too, and the rate of the total variance accounted for is found to be $\% 80.5\left[\mathrm{R}^{2}=.805\right.$; $\mathrm{p}=.000<0.001]$. In addition, the following have a significant effect on the effectiveness of the administrative processes at the schools: teaching field [teaching field=basic education; $\mathrm{B}=-14.909 ; \mathrm{p}=.002<0.001$ ], school type (school type1=primary school1; $\mathrm{B}=15.100$; $\mathrm{p}=.002<0.01$ ), the number of teachers [the number of teachers $1=1-20$ teachers; $\mathrm{B}=-6.684$; $\mathrm{p}=.008<0.01$ ], socioeconomic status [socioeconomic status $1=\mathrm{low} ; \mathrm{B}=4.777 ; \mathrm{p}=.011<0.05$ ], positivist administration approach $[\mathrm{B}=3.474 ; \mathrm{p}=.000<0.001]$, facilitating bureaucracy $[\mathrm{B}=2.036 ; \mathrm{p}=.000<0.001]$ and long term efficacy $[\mathrm{B}=-.904 ; \mathrm{p}=.000<0.001]$. The effect size of the sixth model is found to be high, $f^{2}=\left(\mathrm{r}_{2}^{2}-\mathrm{r}_{1}^{2}\right) /\left(1-\mathrm{r}_{1}{ }^{2}\right)=[(0.808-0.814) /(1-0.814)]=0.03$. The results of the analysis of this model indicate that facilitating bureaucracy, a positivist administration approach, and long-term efficacy as a cultural value have significant effects on the administrative processes.

\section{Discussion, conclusion, and suggestions}

In this study, the effects of the administrative approach, bureaucratic structure, and cultural values on the administrative processes of educational institutions were examined. 
The study's findings show that the teachers mostly have a high level of perception about the facilitating bureaucratic structure at the schools where they were working. Their perceptions about the obstructive bureaucratic structure, on the other hand, are found to be at lower levels. Similar to these findings, Özer (2010) stated that the facilitating bureaucratic structure is dominant at the schools and that the teachers sometimes perceive an obstructive bureaucratic structure. Other findings also report a higher level of perceptions about the facilitating bureaucratic structure (Alev, 2019; Buluç, 2009; Kotnis, 2004; Messick, 2012; Y1lmaz \& Beycioğlu, 2017). It is reported that there is a supportive, democratic, and fair environment for teachers (Messick, 2012; Y1lmaz \& Beycioğlu, 2017). However, some studies report higher levels of perception about the obstructive bureaucratic structure at the schools (Cerit, 2012; Karaman \& Ak11, 2004). It is reported that primary schools have a more obstructive bureaucratic structure (Cerit, 2012).

In schools with an obstructive bureaucratic structure, strict rules and regulations compel teachers, and close supervision and punishment mechanisms are used more effectively (Hoy \& Sweetland, 2001). The present study found that facilitating bureaucracy improves the efficiency of the administrative processes at schools and obstructive bureaucracy decreases the effectiveness of these processes. Although structural characteristics of the schools are shown to differ (Hoy, 2003; Hoy \& Miskel, 2010; Hoy \& Sweetland, 2000,2001; Sinden et al.,2004), the schools should adopt a facilitating bureaucratic structure rather than an obstructive structure (Hoy \& Sweetland, 2001). Weick and Sutcliffe (2001) argue that the facilitating bureaucratic structure of schools positively affects colleague cooperation among teachers and contributes positively to academic success. Wu et al. (2013) also state that under the facilitating school structure, the school administrators and teachers act in cooperation, take decisions together to solve problems and that the school administrators support structures in which teachers can work more effectively. Watts (2009) remarks that an increase in the facilitating school structure improves the organizational sensitivity of employees. Özer (2010) emphasizes that the facilitating bureaucratic structure positively affects organizational norms and vitality. McGuigan and Hoy (2006) state that the increase in the perception of the facilitating bureaucratic structure at schools directly affects the employees' academic optimism levels, improving students' academic achievement. Antonelli (2005) draws attention to the positive effects of the facilitating bureaucratic structure of schools on positive school climate, collective self-efficacy, and school effectiveness. On the other hand, Dzubay (2001) states 
that when school employees are forced to obey certain rules, the obstructive bureaucracy reduces their motivation and causes negative reactions. Based on the previous findings and the findings of this study, it is safe to argue that, unlike the obstructive bureaucratic structure, the facilitating bureaucratic structure increases the sensitivity and commitment of the employees to both the organization and their work. In addition, the facilitating bureaucratic structure positively affects the cooperation, organizational climate, and organizational effectiveness and thus, contributes positively to the effectiveness of the administrative processes in the organization. These findings support the $\mathrm{H}_{1}$ of the study.

The study's findings suggest that the teachers mostly think that there is a high level of positivist administration approach at the schools where they worked. The participants rarely perceive a chaotic administrative approach at the schools. At the same time, it is found in the study that both the positivist administrative approach and the chaotic administrative approach have a positive relationship with the administrative processes. However, it is also found that the positivist administrative approach contributes to the effectiveness of the administrative processes at a higher level than the chaotic administrative approach. Similarly, the findings obtained in studies showing that the administrative approach affects organizational and behavioral outputs support the idea that the administrative approach affects the administrative processes at the schools (Ayral \& Tanrı̈ğen, 2020; Usta, 2013). Ayral and Tanrı̈ğen (2020) emphasize that administrative activities are carried out more transparently in educational organizations where an optimistic perspective towards to employees is dominant. Usta (2013) states that both positivist and chaotic administrative approaches in organizations increase employees' organizational commitment (Usta, 2013). Styhre (2001) draws attention to self-organizing models open to continuous change, development, and transformation in organizations with a chaotic management approach. Tetenbaum (1998) states that the concepts of innovation, creativity, teamwork, project management, respect for differences, and values that need to be protected come to the fore in today's rapidly spreading information and communication context, and it is a necessity to establish an organization with a chaotic structure that can adapt to the sudden developments and changes and build a culture of chaos. On the other hand, Tuz (2004) states that hierarchy and control are important in realizing organizational activities in organizations where the positivist administrative approach is dominant. Açıalın (1995) states that in organizations with a positivist administrative approach, the administrator owes his success to his authority and serves the purpose of preserving the current status quo. Demirtaş (2006) also stated that 
both administrative approaches contain each other to a certain extent. The managers of contemporary organizations, which have the characteristics of development, size, and complexity, should also have the ability to manage this complexity and chaos. Based on the findings of the previous studies and the present study, it can be stated that both chaotic and positivist administrative approaches may exist in organizations based on the structure and type of organizations. The present study's findings also indicate that the positivist administrative approach is more effective in the administrative processes. It seems to be because educational organizations have a highly developed bureaucracy, as Abbott (1965) stated. In addition, there are regular and consistent rules, predetermined plans and programs, and a stable hierarchical structure at the schools. In addition, it is seen that schools also have a structure that is open to development and transformation, has a vision, is self-organizing, flexible, collaborative, and supports innovation and creativity. In the light of these explanations and the findings, the $\mathrm{H}_{2}$ of the study's confirmed.

Another finding of the study is that the participants have a very high level of perception about the long-term efficacy, avoidance from uncertainty, and collectivism. They also perceive moderate masculinity and low power distance perception at the schools they were working at. Hofstede, Hofstede, and Minkov (2010) state that long-term efficacy organizations are future-oriented, prioritize planning, act pragmatically, and care about cultural values such as dedication, hard work, and savings. Javidan and House (2001) stated that organizations with high uncertainty avoidance adopt a stable and consistent structure based on the formal rules. Yukl (2013) reported that there is a fear of uncertainty and high levels of anxiety and stress in such organizations. He also stated that employees desire a safer, more consistent, and orderly environment instead of flexible, innovative, and risktaking managers. Offerman and Hellmann (1997) argue that in organizations with high uncertainty avoidance, there is less delegation of authority and more use of excessive planning, the implementation, and evaluation of formal rules and procedures. Similarly, in the present study, a higher perception of both the positivist administrative approach and uncertainty avoidance was found, which support each other. As expected in the present study, it is found that, unlike today's environments where individuality, personal rights, and responsibilities are prioritized, the collectivist values appear to be higher as an indicator of the general characteristics of Turkish society. Jackson et al. (2006) emphasize that the employees in organizations where collectivist cultural values are dominant have high work and group commitment levels, exhibit more organizational citizenship behavior, and strive 
to increase their performance. In addition, it is reported that commitment to organizational goals in collectivist cultures facilitates the work of the administrators (Jung \& Avolio, 1999; Triandis et al.,1994). In addition, it is stated that motivation resources for the group or organizational success are used more effectively in these cultures (Kirkman and Shapiro, 2001), which facilitates the creation and maintenance of a strong organizational culture based on common values (collaboration, ethics, social responsibility, etc.) (Yukl, 2013). This study found that the perception about the existence of masculine values at schools is at a moderate level. This indicates that there is still an understanding based on gender discrimination in schools. Hofstede (1980a) stated that masculine cultures have certain characteristics such as assertiveness, ambition, competitiveness, importance to wealth and money, and focus on individual and material success. Sargut (2001) stated that such cultures have aggression, desire to rise, competitive, dominant and oppressive Sargut (2001) stated that such cultures have aggression, desire to rise competitive, dominant and oppressive features. On the other hand, Hofstede (1980a, 2001) noted that feminine cultures are more modest and sensitive and value strong social ties, the quality of life, and the wealth of others. Sargut (2001) states that such cultures are more compassionate, merciful, gentle, and loyal. Yeloğlu (2011) argued that Turkish culture shows masculine characteristics in an individual or geographical sense, not social. He also states that Turkish society shows more feminine characteristics than Western cultures in terms of loyalty to its traditions, respect, and compassion. In the study, the participants have a lower level of perception about the power distance. Hofstede (1980a) argues that in cultures with lower power distance, individuals have a higher opinion of the concepts of independence, equality, and solidarity. On the other hand, Dickson et al. (2003) state that leaders have more authority in cultures with higher power distance, and individuals tend to obey the rules without questioning them. Adsit et al. (1997) reported that individuals hesitate to express their opinions openly in such cultures. Smith et al. (2002) highlight the heavy use of formal procedures and less involvement of employees in decision-making processes in such cultural contexts. The study concluded that there is a positive and significant low-level correlation between the effectiveness of the administrative processes and the following dimensions of cultural values: avoidance from uncertainty, collectivism, power distance, and long-term efficacy. In this study, a low-level correlation was found between the teachers' perceptions of individual cultural values and the effectiveness of the schools' administrative processes. Therefore, it turns out that those cultural values originated from family context and society do not significantly affect the 
participants' perceptions about the administrative processes at the schools. These findings support the $\mathrm{H}_{3}$ of the study.

It is found in the study that the teachers perceived the administrative processes at the schools as highly effective. As a result of the multiple hierarchical regression analysis which was employed to identify the variables affecting the administrative processes, it appears that the facilitating bureaucratic structure, positivist administrative approach, and long-term efficacy as a cultural value at the schools all have a high level of influence on the schools' administrative processes. These variables account for $81 \%$ of the total variance. In addition, it is found that the teaching field of the teachers, the type of school, the number of teachers at the schools, and the student's socio-economic status at the school have a significant effect on the school's administrative processes. Yıldırım and Aç1 (2020) emphasize that the inclusion of teachers in the decision-making process, communication, and evaluation processes to increase the effectiveness of school administrators' administrative processes will improve their perception of the organizational justice at the schools. On the other hand, Kim and Kim (2005) state that the school administrators are central to all basic decisionmaking mechanisms at the schools to facilitate the functioning of their institutional structure, solve problems and be social change agents. Therefore, it can be said that teachers' high perception of the administrative processes at schools is due to school administrators' effective and successful management. These findings confirm the $\mathrm{H}_{4}$ of the study.

The findings indicate that the positivist management approach at schools, the facilitating bureaucratic functioning, and the ability to do reliable long-term planning for the future are effective in the schools' administrative processes. The study's findings also suggest that the effectiveness and success of both school administrators and schools depend on the effectiveness of the administrative processes. In order to implement the administrative processes effectively, the following are needed: Establishing a democratic environment at schools, managing the perception about the differences between teaching fields well, developing policies and practices that can minimize the differences between school types and socio-economic levels of schools, balancing the number of the school administrators in proportion to the number of teachers and students. In order to achieve positive behavioral outcomes such as commitment and improve management processes and organizational and systemic impacts, the following issues need to be considered: Explaining the reasons for sudden and continuous changes, preventing the anxiety and stress in the employees that the chaos and crisis environment will create, monitoring the results of the 
change, facilitating the individual and bureaucratic organizational works, and establishing an environment of stability and trust at schools. In addition, it was concluded in the study that the administrative approach, the bureaucratic structure of the school, and the cultural values reveal the majority of the effectiveness of the administrative processes. Therefore, examining the unexplained variance using different organizational behavior and outputs (i.e., organizational climate and culture, leadership, organizational effectiveness, motivation, job performance, job satisfaction, etc.) employing different research approaches (qualitative, mixed, etc.) may contribute to the field.

Ethics Committee Permission: This study was conducted with permission obtained from the Social and Human Sciences Scientific Research and Publication Ethics Committee of Akdeniz University with the decision numbered 307 dated 17/09/2021.

Conflict of Interest Statement: The authors declare that there is no conflict of interest. Author Contribution: The authors contributed equally to the study.

\section{References}

Abbott, M. (1965).Hierarchical impediments to innovation in educational organizations. In M.Abbott and J. Lovell (Eds.), Change perspectives in educational administration (pp.40-53). Auburn, AL: Auburn University.

Abbott, M., \& Caracheo, F. (1988). Power, authority, and bureaucracy. In N.J. Boyan (Ed.), Handbook of research on educational administration (pp.235-257). New York: Longman.

Açıkalın, A. (1995). Toplumsal, kuramsal ve teknik yönleriyle okul yöneticiliği. Ankara: Personel Geliştirme Merkezi.

Aç11, Y. (2020). Okul yönetiminde yönetim süreçlerinin etkililiği ile örgütsel adalet arasındaki ilişki. Yayınlanmamış yüksek lisans tezi, Necmettin Erbakan Üniversitesi, Konya.

Adsit, D.J., London, M., \& Jones, D. (1997). Cross-cultural differences in upward rating in a multi-cultural company. International Journal of Human Resource Management, 8, $385-401$.

Aiken, L.S., \& West, S.G. (1991). Multiple regression:Testing and interpreting interactions. Newbury Park CA: Sage. 
Akyol, B. (2013). Üniversitelerdeki örgütsel adalet olgusunun öğretim elemanları algılarına göre yönetim süreçleri açısından değerlendirilmesi. Yayımlanmamış doktora tezi, On sekiz Mart Üniversitesi, Çanakkale.

Albayrak, A.S. (2005). Çoklu doğrusal bağlantı halinde en küçük kareler tekniğinin alternatifi yanlı tahmin teknikleri ve bir uygulama. ZKÜ Sosyal Bilimler Dergisi, l(1), 105-126.

Alev, S. (2019). Kolaylaştırıcı okul yapısı ve örgütsel vatandaşlık davranışları arasındaki ilişkinin incelenmesi. OPUS-Uluslararası Toplum Araştırmaları Dergisi, 10(17), 420-443.

Antonelli, L.A. (2005). Organizational and SES predictors of student achievement and school effectiveness. Unpublished doctoral dissertation, St. John's UniversityJamaica, New York.

Aslanargun, E. (2007). Modern eğitim yönetimi anlayışına yönelik eleştiriler ve postmodern eğitim yönetimi. Kuram ve Uygulamada Ĕ̈itim Yönetimi, 50(50), 195-212.

Aydın, M. (2018). Eğitim yönetimi. Ankara: Gazi Kitabevi.

Aydın, E. (2019). Temel eğitim kurumlarl yöneticilerinin görüşlerine göre yönetim süreçlerinin değerlendirilmesi. Yayınlanmamış yüksek lisans tezi, Necmettin Erbakan Üniversitesi, Konya.

Aydoğan, İ.Y. (1998). Özel okullarda yönetim süreçlerinin işleyişi (Kayseri ili örneği). Yayınlanmamış yüksek lisans tezi, Ankara Üniversitesi, Ankara.

Ayral, T., \& Tanrıöğen, A. (2020). Okul müdürlerinin yönetim felsefeleri ile okulların şeffaflık düzeyleri arasındaki ilişki. Journal of International Social Research, 13(75), 585-594.

Balc1, A. (2018). Sosyal bilimlerde araştırma yöntem, teknik ve ilkeler (13.Bask1). Ankara: Pegem Akademi.

Başaran, İ.E. (2008). Türk eğitim sistemi ve okul yönetimi. Ankara: Ekinoks Yayınevi.

Bateman, T.S., \& Snell, S.A. (2013). Management. New York, NY: McGraw-Hill.

Bulaç, A. (1990). Din ve modernizm. İstanbul: Endülüs Yayınları.

Buluç, B. (2009).İlköğretim okullarında bürokratik okul yapısı ile okul müdürlerinin liderlik stilleri arasındaki ilişki. Ĕ̆itim ve Bilim, 34(152), 71-86.

Bursalığlu, Z. (2015). Okul yönetiminde yeni yapı ve davranış. Ankara: Pegem Yayıncılık.

Bush, T. (1995). Theories of Educational Management. London: PCP. 
Büte, M., \& Balcı, A.F. (2010). Bağımsız anaokulu yöneticilerinin bakış açısından okul yönetimi süreçlerinin işleyişi ve sorunlar. Kuram ve Uygulamada Eğitim Yönetimi Dergisi, 16(4), 485-511.

Büyüköztürk, Ş. (2016). Sosyal bilimler için veri analizi el kitabı: Ístatistik, araştırma deseni, spss uygulamalarl ve yorum (22.bask1). Ankara: Pegem Akademi.

Büyüköztürk, Ş., Çakmak, E.K., Akgün, Ö.E., Karadeniz, Ş., \& Demirel, F. (2008). Bilimsel araştırma yöntemleri. Ankara: Pegem Akademi.

Cerit, Y. (2012). Okulun bürokratik yapısı ile sınıf öğretmenlerinin profesyonel davranışları arasındaki ilişki. Kuram ve Uygulamada Ĕ̆itim Yönetimi, 18(4), 497-521.

Cohen, J., Cohen, P.,West, S.G., \& Aiken, L.S.(2003). Applied multiple regression/ correlation analysis for the behavioral sciences. Mahwah, NJ: Erlbaum.

Corwin, R.G., \& Borman, K.M. (1980). School as a workplace: Structural constraints on administration. In N.J. Boyan (Ed.), Handbook of research on educational administration (pp.209-237). New York: Longmen.

Çokluk, Ö., Şekercioğlu, G., \& Büyüköztürk, Ş. (2018). Sosyal bilimler için çok değişkenli istatistik SPSS ve LISREL uygulamalart. Ankara: Pegem Akademi.

Çoruk, A. (2012). Yönetim süreçleri açısından yöneticilerin duygu yönetimi davranışları. Yayınlanmamış doktora tezi, On sekiz Mart Üniversitesi, Çanakkale.

Dess, G.G., \& Picken, J.C. (2000). Changing roles: Leadership in the 21 st century. Organizational Dynamics, 28(3), 18-33.

Demirtaş, H. (2006). Yönetim kuram ve yaklaşımları eğitiminin ilköğretim okulu öğretmenlerinin sınıf yönetimi paradigmalarına etkileri. Eğitimde Politika Analizleri ve Stratejik Araştırmalar Dergisi (INASED), 1(1), 49-70.

Dickson, M.W., Den Hartog, D.N., \& Michelson, J.K. (2003). Research on leadership in a cross-cultural context: Making progress and raising new questions. Leadership Quarterly, 14, 729-768.

Dzubay, D. (2001). Understanding motivation\&supporting teacher renewal. Portland,OR: Northwest Regional Educational Laboratory.

Erdoğan, İ. (2003). Okul yönetimi ve öğretim liderliği. İstanbul: Sistem yayıncılık.

Fayol, H. (1916). Industrial and general administration. Paris: Dunod.

Field, A. (2009). Discovering statistics using SPSS (Third Ed.). London: Sage Publication.

Fraenkel, J.R., \& Wallen, N.E. (2006). How to design and evaluate research in education(6th Ed.). New York: McGraw-Hill. 
Firestone, W.A., \& Herriott, R.E. (1981). Images of organization and the promotion of change. Research in the Sociology of Education and Socialization, 2, 221-260.

Gelfand, M.J., Bhawuk, D.P.S., Nishi, L.H., \& Bechtold, D.J. (2004). In R.J. House, P.J. Hanges, M. Javidan, P.W. Dorfman, \& V. Gupta (Ed.), Leadership, culture, and organizations: The GLOBE study of 62 societies, C.1.Thousand Oaks, CA: Sage, p.437-512.

Gregg, R.T. (1957). The administrative process. In administrative behavior in education, eds, R.F. Campbell and R.R. Gregg. New York: Harper \& Row, Publishers.

Griffin, R.W., \& Moorhead, G. (2014). Organizational behavior: Managing people and organizations. Mason, $\mathrm{OH}$ : South Western Cengage Learning.

Gül, İ. (2017). Yönetim süreçlerinin etkililiği ölçeği: Geçerlik ve güvenirlik çalışması. Journal of Human Sciences, 14(2), 1370-1387.

Hofstede, G. (1980a). Motivation, leadership, and organization: Do American theories apply abroad?. Organizational Dynamics, 9(1), 42-63.

Hofstede, G. (1980b). Culture's consequences: International differences in workrelated values. Beverly Hills, CA: Sage.

Hofstede, G. (1981). Culture and organizations. International Studies of Management \& Organization, 10(4), 15-41.

Hofstede, G. (1983). National cultures in four dimensions. A research-based theory of cultural differences among nations. International Studies of Management \& Organization, 13(12), 46-74.

Hofstede, G. (2001). Culture's consequences: Comparing values, behaviors, institutions and organizations across nations,(2.Edition). London (UK): Sage Publications.

Hofstede, G., \& Bond, M.H. (1988). The Confucius connection: From cultural roots to economic growth. Organizational Dynamics, 16(4), 5-21.

Hoftede, G., Hofstede, G.J., \& Minkov, M. (2010). Cultures and organizations: Software of the mind: Intercultural cooperation and its importance for survival. New York: McGraw-Hill.

Hoy, W.K. (2003). An analysis of enabling and mindful school structures: Some theoretical, research, and practical considerations. Journal of Educational Administration, 41, 87-108.

Hoy, W.K., \& Miskel, C.G. (2010). Educational administration: Theory, research and practice. New York: McGraw-Hill. 
Hoy, W., \& Sweetland, S. (2000). Bureaucracies that work: Enabling, not coercive. Journal of School Leadership, 10(6), 525-541.

Hoy, W.K., \& Sweetland, S.R. (2001). Designing better schools: The meaning and nature of enabling school structure. Educational Administration Quarterly, 37, 296-321.

Jackson, C.L., Colquitt, J.A., Wesson, M.J., \& Zapata-Phelan, C.P. (2006). Psychological collectivism: A measurement validation and linkage to group member performance. Journal of Applied Psychology, 91(4), 884-899.

Jung, D.I., \& Avolio, B.J. (1999). Effects of leadership style and followers' cultural orientation on performance in group and individual task conditions. Academy of Management Journal, 42, 208-218.

Karaman, M.K., \& Ak1l, Ü.G. (2004). Bürokrasi ve ilköğretimde örgütsel sağlık. Afyon Kocatepe Üniversitesi Sosyal Bilimler Dergisi, 6(2), 15-38.

Karasar, N. (2017). Bilimsel araştırma yöntemi: Kavramlar, ilkeler, teknikler (32.basım). Ankara: Nobel Yayıncilık.

Kim, P.E., \& Kim, S. (2005). Profiles of schools administrators in South Korea: A comparative perspective. Educational Management Administration \& Leadership, 33(3), 286-310.

Kirkman, B.L., \& Shapiro, D.L. (2001). The impact of cultural values on job satisfaction and organizational commitment in self managing work teams. Academy of Management Journal, Mississippi State, 44(3), 557-569.

Kluckhohn, F.R., \& Strodtbeck, F.L. (1961). Variations in value orientations. New York: Harper Collins

Kotnis, B. (2004). Enabling bureaucracies in education: A case study of formalization in an urban district and schools. Unpublished doctoral dissertation, The State University of New York at Buffalo- Buffalo, NY.

McGuigan, L., \& Hoy, W.K. (2006). Principal leadership: Creating a culture of academic optimism to improve achievement for all students. Leadership and Policy in Schools, 5(3), 203-229.

Mertler, C.A., \& Vannatta, R.A. (2005). Advanced and multivariate statistical methods:Practical application and interpartion (Third Ed.). Glendale, CA: Pyrczak Publishing.

Messick, P.P. (2012). Examining relationships among enabling school structures, academic optimism and organizational citizenship behaviors. Unpublished doctoral dissertation, Auburn University, Auburn, Alabama, USA. 
Miles, M.B. (1965). Education and innovation: The organization in context. In M. Abbott and J. Lovell (Eds.), Changing perspectives in educational administration (pp.5472). Auburn, AL: Auburn University.

Mintzberg, H.(2014). Örgütler ve yapıları (Ed. A. Aypay). Ankara: Nobel Akademi Yayıncilik.

Offermann, L.R., \& Hellmann, P.S. (1997).Culture's consequences for leadership behavior:National values in action. Journal of Cross Cultural Psychology, 28(3), $342-351$.

Özer, N. (2010). İlköğretim okullarının örgütsel diriklik, bürokratiklik ve örgüt normları açısından analizi. Yayınlanmamış doktora tezi, İnönü Üniversitesi, Malatya.

Özer, N., \& Dönmez, B. (2013). Kolaylaştırıcı okul yapısı ölçeğinin Türkçe formunun psikometrik özelliklerinin yeniden değerlendirilmesi. Pegem Ĕ̆itim ve Öğretim Dergisi, 3(4), 57-68.

Palmberg, K. (2009). Complex Adaptive Systems As Metaphors For Organizational Management. The Learning Organization, 16(6), 483-498.

Robbins, S.P. (1998). Organizational behavior:Concepts, controversies, applications. Upper Saddle, NJ: Allyn and Bacon.

Robbins, S.P., Decenzo, D.A., \& Coulter, M. (2013). Fundamentals of management: Essential concepts and applications. New Jersey: Prentice Hall.

Roscoe, J.T. (1975). Fundamental research statistics for the behavioral sciences (Second Edition). New York: Holt Rinehart \& Winston.

Sargut, A.S. (2001). Kültürlerarası farklılaşma ve yönetim. Ankara: İmge.

Saylık, A. (2019). Hofstede'nin kültür boyutları ölçeğinin Türkçeye uyarlanması: Geçerlik ve güvenirlik çalışması. Uluslararası Türkçe Edebiyat Kültür Eğitim Dergisi, 8(3), 1860-1881.

Scarborough, J. (1998). The origins of cultural differences and their impact on management. Westport, CT: Quorum.

Smith, P.B., Peterson, M.F., Schwartz, S.H., Ahmad, A.H., \& Associates (2002). Cultural values, sources of guidance, and their relevance to managerial behavior: A 47-nation study. Journal of Cross-Cultural Psychology, 33(2), 188-208.

Sinden, J., Hoy, W.K., \& Sweetland, S.R. (2004). Enabling school structures: Principal leadership and organizational commitment of teachers. Journal of School Leadership, 14(2), 195-210. 
Steers, R.M., Sanchez-Runde, C.J., \& Nardon, L.(2010). Management across cultures: Challenges and strategies. Cambridge University Press.

Styhre, A. (2001). The nomadic organization: The postmodern organization of becoming. Tamara: Journal of Critical Postmodern Organization Science, 1(4), 1-12.

Summak, M.S., \& Yazgan, H. (2007). İlköğretim okulu müdürlerinin yönetim süreçlerini kullanma etkinlikleri ile bazı duygusal, sosyal ve ruhsal yeterlilikleri arasındaki ilişkinin incelenmesi (Kilis İli Örneği). Türk Eğitim Bilimleri Dergisi, 5(2), 261-290.

Tabachnick, B.G., \& Fidell, L.S. (2013). Using multivariate statistics (Sixth ed.). United States: Pearson Education

Tetenbaum, T.J. (1998). Shifting paradigms: From Newton to chaos. Organizational Dynamics, Spring, 21-32.

Triandis, H.C. (1995). Individualism and collectivism. Boulder, CO: Westview Press.

Triandis, H.C., Kurowski, L.L., \& Gelfand, M.J. (1994). Workplace diversity. In H.C. Triandis, M.D. Dunnette, \& L.M. Hough (Ed.), Handbook of industrial and organizational psychology, C.4. Palo Alto: Consulting Psychologists Press, p.769827.

Tüz, M.V. (2004). Değişim ve kaos ortamında işletme davranışı. İstanbul: Alfa Akademi.

Usta, M.E. (2013). Okul yöneticilerinin pozitivist ve kaos yönetim anlayışlarını benimsemelerinin kendilerinin ve ögrretmenlerin örgüt sel bağlllık düzeylerine etkileri. Yayınlanmamış doktora tezi, Fırat Üniversitesi, Elâzı̆g.

Usta, M.E. (2017). Yönetim anlayışları ölçeğinin geliştirilmesi. Mukaddime, 8(2), 265-285.

Watts, D.M. (2009). Enabling school structure, mindfulness, and teacher empowerment: Test of a theory. Unpublished doctoral dissertation, The University of AlabamaTuscaloosa, Alabama.

Weick, K.E., \& Sutcliffe, K.M. (2001). Managing the unexpected: Assuring high performance in an age of complexity. San Francisco: Jossey-Bass.

Wu, J.H., Hoy, W.K., \& Tarter, C.J. (2013). Enabling school structure, collective responsibility and a culture of academic optimism: Toward a robust model of school performance in Taiwan. Journal of Educational Administration, 51(2), 176-193.

Yeloğlu, H.O. (2011). Türk toplumsal kültürünün örgüt yapılarına olan etkilerinin belirlenmesine yönelik bir çalışma. Sosyal Bilimler Araştırmaları Dergisi, 2(4), 153170. 
Yıldırım, A., \& Açıl, Y. (2020). Okul yönetiminde yönetim süreçlerinin etkililiği ile örgütsel adalet arasındaki ilişki. Karamanoğlu Mehmetbey Uluslararası Ĕgitim Araştırmaları Dergisi, 2(2), 169-179.

Yılmaz, A.İ., \& Beycioğlu, K. (2017). Teachers' perceptions regarding bureaucratic structures in schools. Anadolu Üniversitesi Eğitim Fakültesi Dergisi, 1(2), 1-23.

Yoo, B., Donthu, N., \& Lenartowicz, T. (2011). Measuring Hofstede's five dimensions of cultural values at the individual level: Development and validation of CVSCALE. Journal of International Consumer Marketing, 23(3-4), 193-210.

Yukl, G. (2013). Leadership in organizations. New Jersey: Pearson, Prentice Hall. 